\title{
Effect of Coordination Geometry on Magnetic Properties in a Series of Cobalt(II) Complexes and Structural Transformation in Mother Liquor
}

Subrata Ghosh, Sujit Kamilya, Mayurika Das, Sakshi Mehta, Marie-Emmanuelle Boulon, Ivan Nemec, Mathieu Rouzières, Radovan Herchel, and Abhishake Mondal*

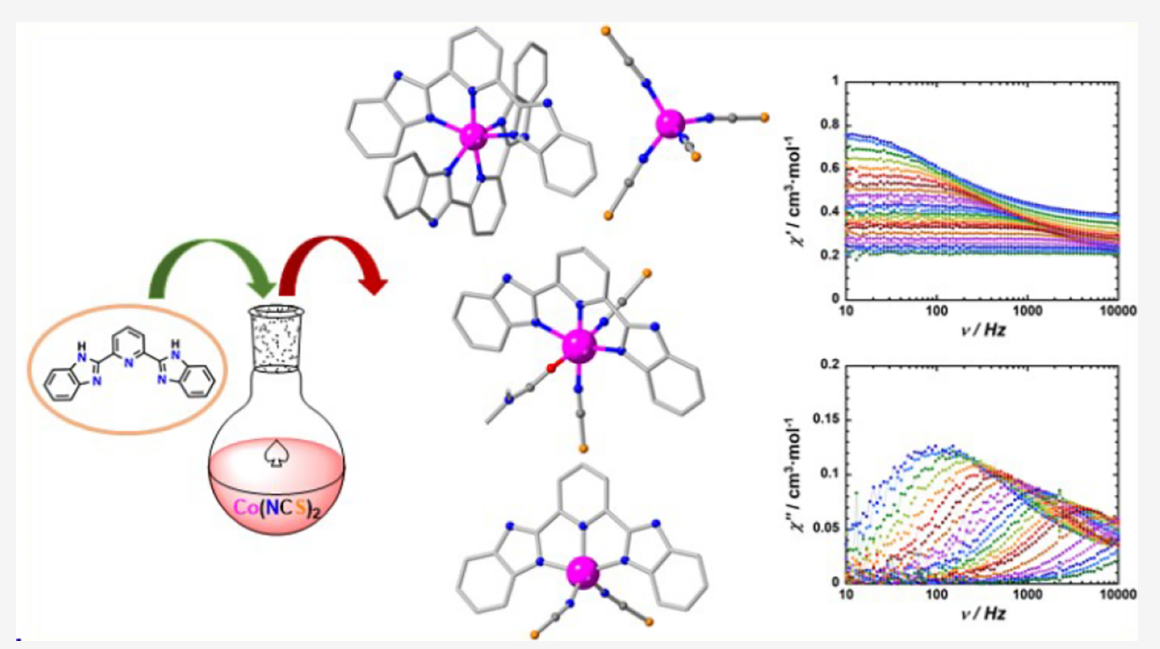

ABSTRACT: The three $\mathrm{Co}(\mathrm{II})$ complexes $\left[\mathrm{Co}(\mathrm{bbp})_{2}\right]\left[\mathrm{Co}(\mathrm{NCS})_{4}\right] \cdot 4 \mathrm{DMF}(\mathbf{1}), \quad\left[\mathrm{Co}(\mathrm{bbp})(\mathrm{NCS})_{2}(\mathrm{DMF})\right] \cdot 2 \mathrm{DMF}(\mathbf{2})$, and $\left[\mathrm{Co}(\mathrm{bbp})(\mathrm{NCS})_{2}\right]$ (3) have been synthesized and characterized by single-crystal X-ray diffraction, magnetic, and various spectroscopic techniques. Complexes 1 and 3 are obtained by the reaction of $\mathrm{Co}(\mathrm{NCS})_{2}$ with 2,6-bis $(1 \mathrm{H}$-benzo[d]imidazol-2$\mathrm{yl}$ )pyridine (bbp), and complex 1 undergoes a structural transformation to form complex 2 . A single-crystal X-ray study revealed that complex 1 is comprised of two $\mathrm{Co}$ (II) centers, a cationic octahedral $\mathrm{Co}$ (II) unit and an anionic tetrahedral $\mathrm{Co}$ (II) unit, while the $\mathrm{Co}(\mathrm{II})$ ion is in a distorted-octahedral environment in $\mathbf{2}$. Moreover, in complex 3, the Co(II) ion is in a distorted-square-pyramidal geometry. The effect of coordination geometry on the magnetic properties was studied by both static and dynamic magnetic measurements. Direct current (dc) magnetic susceptibility measurements showed that all of the Co(II) ions are in high-spin state in these complexes. Alternating current (ac) magnetic susceptibility measurements indicated that complexes 2 and $\mathbf{3}$ display slow relaxation of magnetization in an external dc magnetic field, while complex 1 displayed no such property. EPR experiments and theoretical calculations were consistent with the above findings.

\section{INTRODUCTION}

Bistable magnetic materials based on transition metals have achieved enormous attention over the past few decades, particularly materials exhibiting slow relaxation of magnetization, ${ }^{1-3}$ e.g. single-molecule magnets (SMMs) and singlechain magnets (SCMs), due to their potential applications in the fields of quantum computing, information storage, and molecular spintronics. ${ }^{4-6}$ Magnetic anisotropy $(D)$ and ground state spin $(S)$ produce energy differences to reverse the magnetization, which is the origin of slow magnetic relaxation. The effective energy barrier is defined by $\Delta_{\text {eff }}=S^{2}(D)$ or $\left(S^{2}\right.$ $-1 / 4)(D)$ for molecules with integer or noninteger ground spin states, respectively. In order to achieve a significant energy barrier, researchers sought giant spin systems. ${ }^{7-9}$ However, the desired value of energy barrier was not obtained effectively, as the value of $D$ varied inversely with $S$. Recently interest has shifted to enhancing the anisotropy barrier associated with the single metal center. ${ }^{10,11}$ After the discovery of lanthanide 
Scheme 1. Schematic Presentations (Top) and Pictures of Crystals (Bottom) of Complexes 1-3

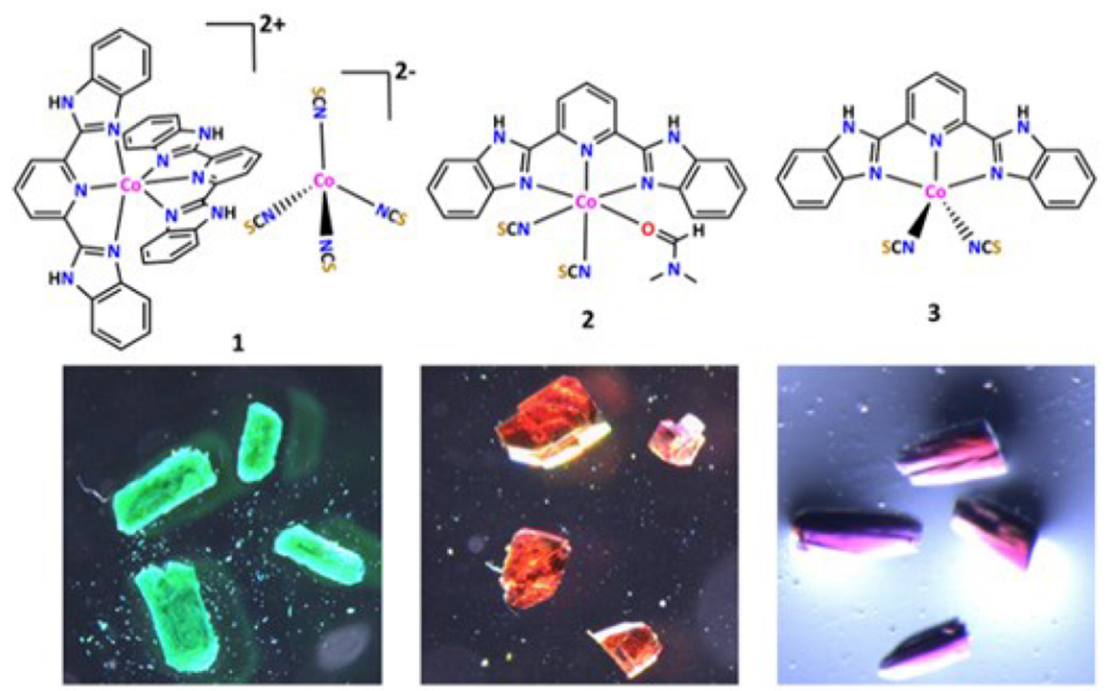

complex based mononuclear SMMs, ${ }^{12-15}$ several mononuclear complexes with the $3 \mathrm{~d}$ transition metals $\mathrm{V}, \mathrm{Cr}, \mathrm{Mn}, \mathrm{Fe}, \mathrm{Ni}$, and $\mathrm{Cu}$ have been studied. ${ }^{16-20}$ Great interest has been devoted to $\mathrm{Co}(\mathrm{II})$ due to its high magnetic anisotropy, strong first-order spin-orbit coupling, and noninteger ground spin state $(S=3$ / $2)$, which conceals quantum tunneling of magnetization (QTM). ${ }^{10,11,20}$ In this aspect, mononuclear Co(II) complexes exhibiting slow relaxation of magnetization have been observed in numerous coordination geometries and coordination numbers such as two, three, four, five, six, seven, and eight. $^{20-31}$ Despite major improvements in mononuclear Co(II)-based SMMs over the past few years, an appropriate relationship between the structural parameters and magnetic properties in Co complexes is still challenging. Intense research is needed to extend our understanding for the rational design of desired magnetic materials.

To explore such aspects, herein we disclose a detailed investigation of magneto-structural chemistry in a series of mononuclear cobalt(II) complexes based on the tridentate bbp ligand $(\mathrm{bbp}=2,6$-bis $(1 \mathrm{H}$-benzo $[d]$ imidazol-2-yl $)$ pyridine $)$ through preparation, detailed physical characterization including X-ray structure analyses, magnetic measurements, and EPR studies, and theoretical calculations. The studies reveal the effect of the coordination geometry on the magnetic properties of $\mathrm{Co}(\mathrm{II})$ complexes.

\section{EXPERIMENTAL SECTION}

Materials and Physical Measurements. All manipulations were carried out under an argon atmosphere using standard Schlenk techniques unless otherwise stated. Solvents were dried by standard methods and freshly distilled prior to use. All chemicals were used as purchased from chemical sources without further purification. The ligand bbp was synthesized according to a literature procedure. ${ }^{32}$ The crystals of the complexes were removed from the mother liquor and dried on filter paper to remove any adhering solvent, prior to measurement. The elemental analyses of $\mathrm{C}, \mathrm{H}$, and $\mathrm{N}$ were performed with a Thermo Scientific Flash 2000 Organic Elemental Analyzer. Infrared (IR) spectra were recorded in the range of $4000-400 \mathrm{~cm}^{-1}$ on a Bruker Tensor 27 spectrometer. UV/vis/NIR spectra were carried out in the region of $250-2000 \mathrm{~nm}$ on a Lambda $750 \mathrm{UV} / \mathrm{vis} /$ NIR spectrometer. The UV/vis spectroscopic measurements in solution were done in quartz cuvettes with a path length of $1 \mathrm{~cm}$. Solid-state measurements were carried out by taking a 5\% sample by weight in $\mathrm{KBr}$. Thermogravimetric analysis (TGA) was done on a
Mettler Toledo TGA/SDTA851 analyzer with a heating rate of $5{ }^{\circ} \mathrm{C}$ $\mathrm{min}^{-1}$ ranging from room temperature to $300{ }^{\circ} \mathrm{C}$ under a nitrogen atmosphere. Differential scanning calorimetry (DSC) measurements were performed using a Mettler Toledo DSC $823^{\mathrm{e}}$ differential scanning calorimeter with a scan rate of $5 \mathrm{~K} \mathrm{~min}^{-1}$ under a nitrogen atmosphere. Powder X-ray diffraction (PXRD) measurements were carried out on a PANalytical Empyrean diffractometer at $45 \mathrm{kV}$ and $30 \mathrm{~mA}$, under $\mathrm{Cu} \mathrm{K} \alpha$ radiation $(\lambda=1.54059 \AA)$. PXRD data analyses were done using PANalytical X'Pert HighScore Plus software. ${ }^{33}$ Cyclic voltammetry $(\mathrm{CV})$ measurements were performed with a Metrohm Autolab PGSTAT101 instrument using platinum as the working electrode in DMF (for the bbp ligand and complexes 1-3) and DCM (for complex 3) with $0.1 \mathrm{M}^{n} \mathrm{Bu}_{4} \mathrm{NPF}_{6}$ as the supporting electrolyte with a scan rate of $0.1 \mathrm{~V} / \mathrm{s}$. The concentration of the complexes used is around $1 \mathrm{mM}$. Ferrocene was used as an internal reference. EPR analyses were done using an EMX Bruker spectrometer equipped with a dielectric resonator. The temperature was monitored using an Intelligent Temperature Controller from Oxford Instrumentation employing a ${ }^{4} \mathrm{He}$ flow cryostat. For measurement of powders, the sample was ground to avoid microcrystallinity and eventual preferential orientation effects were checked by rotating the tube in the cavity and double-measuring the spectra. The powdered sample was installed in $4 \mathrm{~mm}$ diameter quartz tubes. The EPR data were analyzed with the help of EasySpin software. $^{34}$

Synthesis of Complexes: [Co(bbp) $\left.)_{2}\right]\left[\mathrm{Co}(\mathrm{NCS})_{4}\right] \cdot 4 \mathrm{DMF}$ (1), $\left[\mathrm{Co}(\mathrm{bbp})(\mathrm{NCS})_{2}(\mathrm{DMF})\right] \cdot 2 \mathrm{DMF}(2)$, and [Co(bbp)(NCS) $\left.{ }_{2}\right]$ (3). Under an argon atmosphere, $\mathrm{Co}(\mathrm{NCS})_{2}(35 \mathrm{mg}, 0.2 \mathrm{mmol})$ was suspended in dry DCM $(10 \mathrm{~mL})$. A solution of bbp $(62 \mathrm{mg}, 0.2$ $\mathrm{mmol})$ in a mixture of dry $\mathrm{MeOH}$ and dry DCM $(1 / 2)(18 \mathrm{~mL})$ was added. The resulting reaction mixture was stirred overnight. The yellow-green precipitate was filtered off, giving a pink filtrate. Green crystals of 1 were obtained in $47 \%$ yield from slow diffusion of diethyl ether into a green solution of the obtained precipitate in a mixture of DMF and acetone (7/1). Red crystals of 2 were obtained after a long standing (approximately 20 days) of green crystals of $\mathbf{1}$ in the mother solution. Slow evaporation of the pink filtrate gave analytically pure pink crystals of 3 in $35 \%$ yield. Scheme 1 shows schematic presentations and pictures of crystals of complexes 1-3. Data for 1, $\mathrm{C}_{54} \mathrm{H}_{54} \mathrm{Co}_{2} \mathrm{~N}_{18} \mathrm{O}_{4} \mathrm{~S}_{4}$ (1265.25), are as follows. Anal. Calcd: C, 51.26; H, 4.30; N, 19.93. Found: C, 50.85; H, 4.69; N, 19.87. ATR-IR (only intense bands): $\nu\left(\mathrm{cm}^{-1}\right)$ 3084, 2100, 2059, 1671, 1638, 1591, 1574, $1491,1458,1414,1374,1315,1251,1234,1160,1105,1060,995$, $967,902,846,817,802,745,665,583,477,413$. Data for 2, $\mathrm{C}_{30} \mathrm{H}_{34} \mathrm{CoN}_{10} \mathrm{O}_{3} \mathrm{~S}_{2}$ (705.72), are as follows. Anal. Calcd: C, 51.06; $\mathrm{H}$, 4.86; N, 19.85. Found: C, 50.81; H, 5.00; N, 19.76. ATR-IR (only intense bands): $\nu\left(\mathrm{cm}^{-1}\right)$ 3056, 2991, 2875, 2072, 2052, 1913, 1834, 
Table 1. X-ray Crystallographic Data for Complexes 1-3

\begin{tabular}{|c|c|c|c|}
\hline & 1 & 2 & 3 \\
\hline CCDC no. & 1916563 & 1916572 & 1916573 \\
\hline empirical formula & $\mathrm{C}_{54} \mathrm{H}_{54} \mathrm{Co}_{2} \mathrm{~N}_{18} \mathrm{O}_{4} \mathrm{~S}_{4}$ & $\mathrm{C}_{30} \mathrm{H}_{34} \mathrm{CoN}_{10} \mathrm{O}_{3} \mathrm{~S}_{2}$ & $\mathrm{C}_{21} \mathrm{H}_{13} \mathrm{CoN}_{7} \mathrm{~S}_{2}$ \\
\hline formula wt & 1265.25 & 705.72 & 486.45 \\
\hline temp $(\mathrm{K})$ & $120(2)$ & $293(2)$ & $120(2)$ \\
\hline cryst syst & triclinic & triclinic & triclinic \\
\hline space group & $P \overline{1}$ & $P \overline{1}$ & $P \overline{1}$ \\
\hline$a(\AA)$ & $10.4390(4)$ & $11.6648(17)$ & $9.4850(6)$ \\
\hline$b(\AA)$ & $17.1419(6)$ & $11.8019(17)$ & $9.8536(7)$ \\
\hline$c(\AA)$ & $17.3692(6)$ & $12.8244(18)$ & $11.3697(8)$ \\
\hline$\alpha(\operatorname{deg})$ & $90.118(2)$ & $95.193(7)$ & 100.998(3) \\
\hline$\beta(\operatorname{deg})$ & $103.278(2)$ & $98.785(7)$ & $91.074(3)$ \\
\hline$\gamma(\operatorname{deg})$ & $93.755(2)$ & $92.871(7)$ & $106.602(3)$ \\
\hline$V, \AA^{3}$ & $3018.07(19)$ & $1734.0(4)$ & $996.59(12)$ \\
\hline Z & 2 & 2 & 2 \\
\hline$d_{\text {calcd }}\left(\mathrm{g} \mathrm{cm}^{-3}\right)$ & 1.392 & 1.352 & 1.621 \\
\hline$\mu\left(\mathrm{mm}^{-1}\right)$ & 0.748 & 0.661 & 1.096 \\
\hline$F(000)$ & 1308 & 734 & 494 \\
\hline$\theta_{\max }(\mathrm{deg})$ & 25.399 & 27.484 & 25.398 \\
\hline completeness (\%) & 99.8 & 99.8 & 99.9 \\
\hline no. of rflns collected & 11102 & 7913 & 3661 \\
\hline no. of indep rflns & 8950 & 4550 & 2977 \\
\hline goodness of fit on $F^{2}$ & 1.044 & 1.000 & 1.022 \\
\hline \multirow[t]{2}{*}{ final $R$ indices $(I>2 \sigma(\mathrm{I}))^{a}$} & $\mathrm{R} 1=0.0600$ & $\mathrm{R} 1=0.0620$ & $\mathrm{R} 1=0.0326$ \\
\hline & $\mathrm{wR} 2=0.1479$ & $\mathrm{wR} 2=0.1313$ & $\mathrm{wR} 2=0.0689$ \\
\hline \multirow[t]{2}{*}{ final $R$ indices (all data) ${ }^{a}$} & $\mathrm{R} 1=0.0762$ & $\mathrm{R} 1=0.1196$ & $\mathrm{R} 1=0.0465$ \\
\hline & $\mathrm{wR} 2=0.1576$ & $\mathrm{wR} 2=0.1568$ & $\mathrm{wR} 2=0.0740$ \\
\hline
\end{tabular}

$1789,1642,1606,1493,1460,1385,1317,1253,1235,1160,1146$, $1105,1064,993,967,938,905,846,817,753,694,666,628,584$, 536, 480, 459, 433. Data for $3, \mathrm{C}_{21} \mathrm{H}_{13} \mathrm{CoN}_{7} \mathrm{~S}_{2}(486.45)$, are as follows. Anal. Calcd: C, 51.85; H, 2.69; N, 20.16. Found C, 51.62; H, 2.97; N, 20.01. ATR-IR (only intense bands): $\nu\left(\mathrm{cm}^{-1}\right) 3088,2103$, 2077, 1625, 1590, 1571, 1454, 1398, 1312, 1234, 1145, 1116, 1086, 1015, 993, 947, 931, 909, 895, 812, 762, 733, 655, 581, 567, 468, 425.

Magnetic Measurements. The magnetic susceptibility measurements were performed with a Quantum Design MPMS-XL SQUID magnetometer, between 1.8 and $300 \mathrm{~K}$ for dc applied fields ranging from -7 to $7 \mathrm{~T}$ for $\mathbf{1}$ and 3 . For complex 2, magnetic susceptibility measurements were carried out with a Quantum Design MPMS-XL SQUID magnetometer and a Quantum Design PPMS EverCool-II apparatus, between 1.8 and $300 \mathrm{~K}$ and between 2.5 and $280 \mathrm{~K}$, respectively, for $\mathrm{dc}$ applied fields ranging from -7 to $7 \mathrm{~T}$ in mother liquor. Polycrystalline samples of $1-3(11.10,15.27$, and $5.71 \mathrm{mg}$, respectively) placed in a polyethylene bag $(2.4 \times 0.6 \times 0.02 \mathrm{~cm})$ were subjected to measurements. The temperature-dependent data were measured using a 2500 Oe dc field for 1 and a 1000 Oe dc field for 2 and 3. The isothermal magnetization data were acquired at 3 and $5 \mathrm{~K}$ for 1 , at $2.5,3,5$, and $8 \mathrm{~K}$ for 2 , and at 4 and $6 \mathrm{~K}$ for 3 . The ac susceptibility measurements were carried out with an oscillating ac field of 3 Oe with frequency ranging from 1 to $1500 \mathrm{~Hz}$ (for 1 and 3) and from 1 to $10000 \mathrm{~Hz}$ (for 2). The frequency dependence was measured at different external dc magnetic fields ranging from 500 to $6000 \mathrm{Oe}$ at $1.8 \mathrm{~K}$ (for 1 and 3 ) and from 0 to 10000 Oe at $2 \mathrm{~K}$ (for 2). $M$ vs $H$ measurements were performed at $100 \mathrm{~K}$ to check for the presence of ferromagnetic impurities, which were found to be absent. The magnetic data were corrected for the sample holder and the diamagnetic contribution.

X-ray Crystallography. Single-crystal X-ray structure analysis data of complexes 1-3 were collected with a Bruker SMART APEX CCD diffractometer equipped with graphite-monochromated Mo K $\alpha$ radiation $(\lambda=0.71073 \AA)$. The single crystals were mounted on crystal mounting loops with the help of Paratone oil at $240 \mathrm{~K}$ and slowly cooled to $120 \mathrm{~K}$ at a $2 \mathrm{~K} / \mathrm{min}$ ramping rate, followed by data collection at $120 \mathrm{~K}$ for $\mathbf{1}$ and 3. For complex 2, data collection was done at $293 \mathrm{~K}$. Data integration and reduction were performed with the help of SAINT software, and empirical absorption corrections were applied with the SADABS program. ${ }^{35}$ Structures were solved using direct methods and refined with a full-matrix least-squares method on $F^{2}$ using SHELXL-2014. ${ }^{36}$ All non-hydrogen atoms were refined using anisotropic displacement parameters. Hydrogen atoms were located in ideal positions and refined isotropically using a riding model. Crystal data and refinement parameters are given in Table 1. Selected bond lengths and bond angles are given in Table S1. Nonroutine aspects of structure refinement are as follows. One of the $\mathrm{NCS}^{-}$ligands on the $\left[\mathrm{Co}(\mathrm{NCS})_{4}\right]^{2-}$ anion in 1 is dynamically disordered. We modeled this issue as a disorder over three positions with fixed occupation factors $(0.3: 0.5: 0.2)$. The values of the occupation factors were determined using the SUMP instruction in the refinement. One of the noncoordinated DMF molecules exhibits large thermal movement, but attempts to model it as a disorder over two positions did not result in any improvements, and therefore the potential disorder of this molecule was left unresolved in the final refinement.

Theoretical Calculations. The ORCA 4.1 computational package was used for quantum chemical calculations. ${ }^{37,38}$ First, the molecular structures of $\left[\mathrm{Co}(\mathrm{bbp})_{2}\right]^{2+}$ and $\left[\mathrm{Co}(\mathrm{NCS})_{4}\right]^{2-}$ of $1,[\mathrm{Co}(\mathrm{bbp})-$ $\left.(\mathrm{NCS})_{2}(\mathrm{DMF})\right]$ of 2 , and $\left[\mathrm{Co}(\mathrm{bbp})(\mathrm{NCS})_{2}\right]$ of 3 were extracted from X-ray data and the positions of hydrogen atoms were optimized with the DFT method using the PBE functional. Next, calculations of the zero-field splitting (ZFS) parameters were carried out using state average complete active space self-consistent field (SA-CASSCF) ${ }^{39}$ wave functions complemented by $N$-electron valence second-order perturbation theory (NEVPT2) $)^{40,41}$ using the triple- $\zeta$ basis set def2$\mathrm{TZV}^{42}$ for all atoms. In the state-averaged approach all multiplets for a given electron configuration were equally weighted. The ZFS parameters, based on dominant spin-orbit coupling contributions from excited states, were calculated through quasi-degenerate perturbation theory (QDPT) ${ }^{43}$ in which an approximation to the Breit-Pauli form of the spin-orbit coupling operator (SOMF 
Scheme 2. Synthesis of 1-3

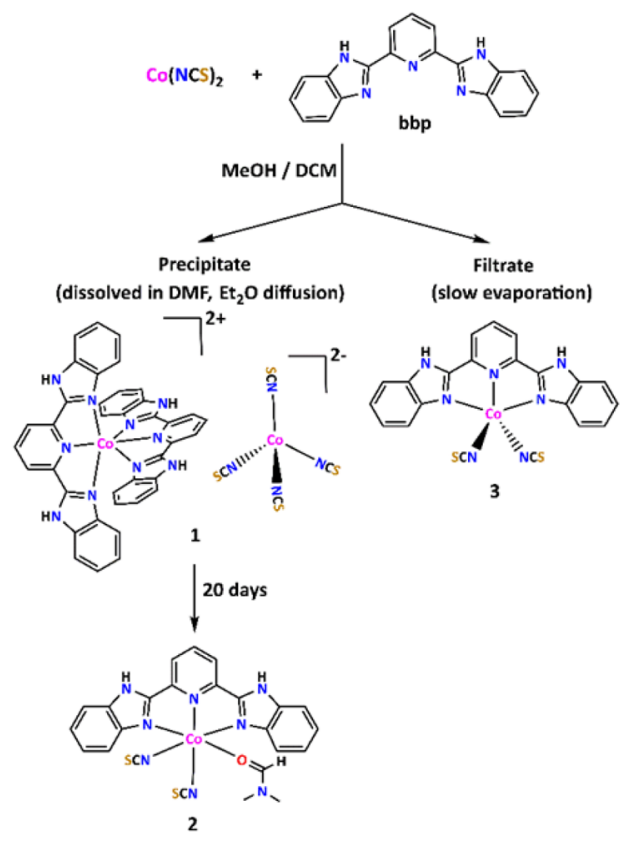

$2\left[\mathrm{Co}(\mathrm{bbp})(\mathrm{NCS})_{2}(\mathrm{DMF})\right] \stackrel{\mathrm{DMF} / \mathrm{Acetone}}{\text { slow }}\left[\mathrm{Co}(\mathrm{bbp})_{2}\right]\left[\mathrm{Co}(\mathrm{NCS})_{4}\right] \stackrel{\mathrm{DMF} / \mathrm{Acetone}}{\underset{\text { fast }}{\stackrel{\mathrm{D}}{2}} 2 \mathrm{Co}(\mathrm{NCS})_{2}}+2 \mathrm{bbp} \stackrel{\mathrm{DCM} / \mathrm{MeOH}}{\longrightarrow} 2\left[\mathrm{Co}(\mathrm{bbp})(\mathrm{NCS})_{2}\right]$

approximation $)^{44}$ and the effective Hamiltonian theory ${ }^{45}$ were utilized. The calculations utilized the RIJCOSX approximation with the auxiliary basis sets $\operatorname{def} 2 / \mathrm{J}^{46}$ and def2-TZVP/C. ${ }^{47}$ Increased integration grids (Grid6 and GridX6 in ORCA convention) and tight SCF convergence criteria were used in all calculations. Ab initio ligand field theory (AILFT) was utilized for energy calculations of $d$ orbitals. $^{48,49}$ Moreover, recently introduced dynamic correlation dressed CAS with a second-order treatment (DCD-CAS(2)) was also utilized to calculate ZFS parameters as well, where the spin-orbit and the spin-spin interactions were included. ${ }^{50}$

\section{RESULTS AND DISCUSSION}

Synthesis. Complexes $\mathbf{1}$ and $\mathbf{3}$ were prepared by the reaction of $\mathrm{Co}(\mathrm{NCS})_{2}$ and the bbp ligand in a mixture of DCM and $\mathrm{MeOH}$ (Scheme 2). Slow diffusion of diethyl ether into the solution of the reaction precipitate in a mixture of DMF and acetone gave green crystals of 1 . Pink crystals of 3 were obtained from slow evaporation of the reaction filtrate. Green crystals of complex 1 on prolonged standing in mother solution (DMF/acetone) converted to red crystals of $\mathbf{2}$ through a structural transformation. In summary, the observed transformations can be described best by a simple reaction equation with two kinetically different steps in the crystallization of the reaction precipitate from DMF/acetone (Scheme 2), whereas a slower step involves solvolysis of the $\left[\mathrm{Co}(\mathrm{bbp})_{2}\right]^{2+}$ and $\left[\mathrm{Co}(\mathrm{NCS})_{4}\right]^{2-}$ molecules, resulting in the formation of $\left[\mathrm{Co}(\mathrm{bbp})(\mathrm{DMF})(\mathrm{NCS})_{2}\right]$.

The purity of all complexes was confirmed by elemental analyses and PXRD measurements (Figures S1-S3). The thermal stabilities of all complexes were studied by TGA up to $300{ }^{\circ} \mathrm{C}$ (Figure S4). Complexes 1 lost two crystallized DMF molecules around $125^{\circ} \mathrm{C}$ and one crystallized DMF molecule around $185^{\circ} \mathrm{C}$, whereas complex 2 started to lose a crystallized DMF molecule above $80{ }^{\circ} \mathrm{C}$. However, complex 3 is stable in the measured temperature range. The complexes have been well characterized by IR, UV/vis/NIR, and electrochemistry (Figures S6-S14).

Structure Analysis. Single-crystal X-ray diffraction analysis was performed on suitable single crystals of 1 and 3 at $120 \mathrm{~K}$ and 2 at $293 \mathrm{~K}$. Complex 1 crystallizes in triclinic space group $P \overline{1}$. Its crystal structure consists of a cationic $\left[\mathrm{Co}(\mathrm{bbp})_{2}\right]^{2+}$ unit, an anionic $\left[\mathrm{Co}(\mathrm{NCS})_{4}\right]^{2-}$ unit, and four molecules of crystallized DMF (Figure 1). The overall coordination

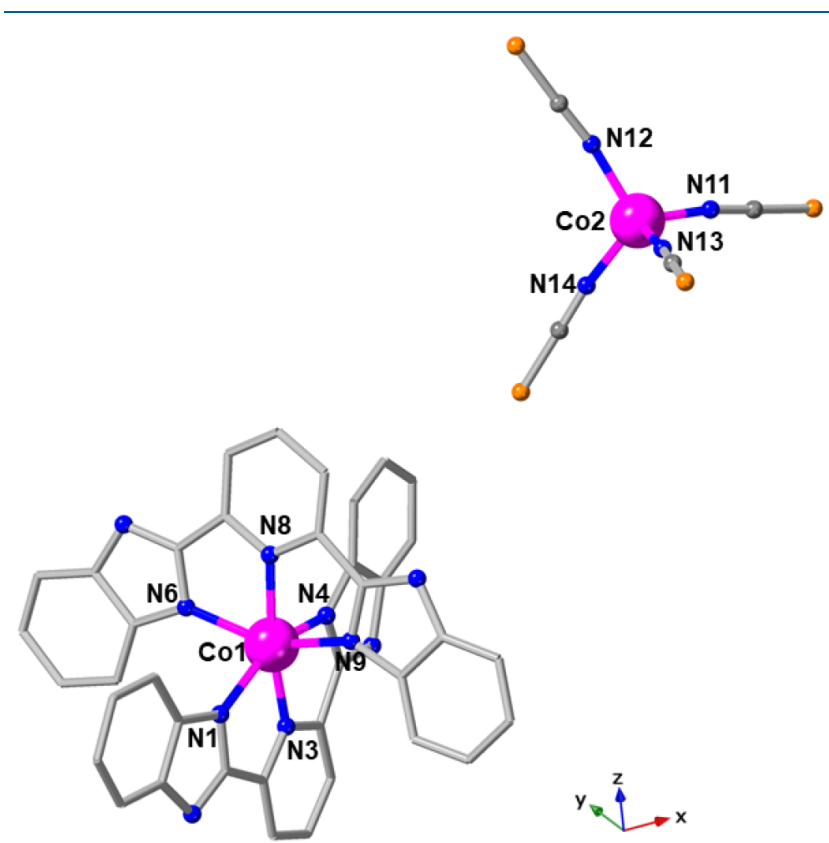

Figure 1. Perspective view of complex 1. Hydrogen atoms and solvent molecules are omitted for clarity ( $\mathrm{Co}$, pink; $\mathrm{C}$, gray; N, blue; $\mathrm{S}$, orange). 

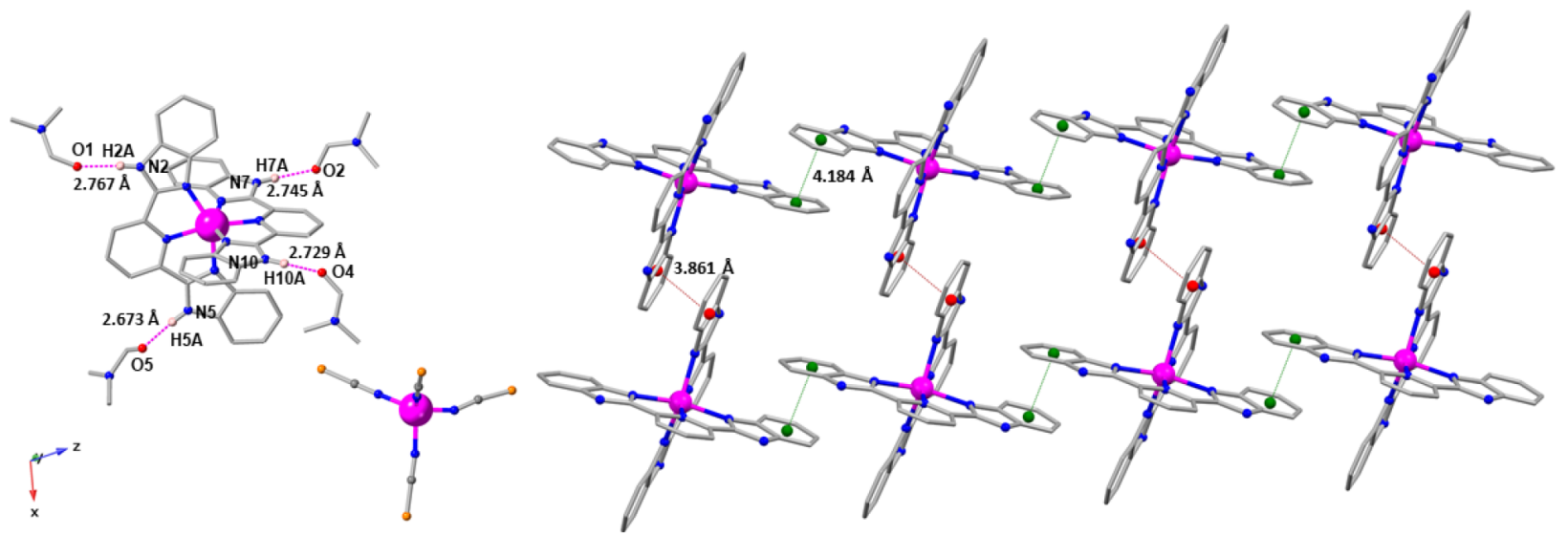

Figure 2. Perspective views of the molecular structure of 1 displaying $\mathrm{N}-\mathrm{H} \cdots \mathrm{O}$ hydrogen bonds (violet dotted lines) (left) and the supramolecular double chain formed by weak intermolecular $\pi \cdots \pi$ interactions (red and green dotted lines) (right). Hydrogen atoms, solvent molecules, and counteranions are omitted for clarity.

geometry of the cationic $\left[\mathrm{Co}(\mathrm{bbp})_{2}\right]^{2+}$ unit of $\mathbf{1}$ is best described as a distorted octahedron with a $\mathrm{CoN}_{6}$ environment using the continuous shape measures (CShM) program ${ }^{51}$ (Table S2), where the cobalt center is coordinated to six nitrogen donor atoms of two mutually perpendicular bbp ligands. An angular distortion of $\left[\mathrm{Co}(\mathrm{bbp})_{2}\right]^{2+}$ is observed in the $\mathrm{N}-\mathrm{Co}-\mathrm{N}$ angles. The $\mathrm{N}-\mathrm{Co}-\mathrm{N}$ angles for the nitrogen atoms in cis arrangements are in the range of 75.7-116.2 while those in a trans disposition are in the range of 150.7$168.1^{\circ}$. The $\mathrm{Co}-\mathrm{N}$ bond lengths to the central pyridyl rings (2.092(3) and 2.090(4) $\AA$ ) are slightly shorter than those involving the outer benzimidazolyl rings $(2.140(3)-2.177(3)$ A). The average $\mathrm{Co}-\mathrm{N}$ bond length of $2.138 \AA$ A suggested a HS state of the central $\mathrm{Co}$ (II) atom. The coordination geometry of the $\left[\mathrm{Co}(\mathrm{NCS})_{4}\right]^{2-}$ complex anion in $\mathbf{1}$ is best described as a distorted-tetrahedral geometry (Table S2) with an average $\mathrm{N}-$ $\mathrm{Co}-\mathrm{N}$ angle of $109.9^{\circ}$ and average $\mathrm{Co}-\mathrm{N}$ bond length of $1.946 \AA$. The coordinated thiocyanate anions are almost linear with an average $\mathrm{N}-\mathrm{C}-\mathrm{S}$ angle of $178.5^{\circ}$; however, the Co$\mathrm{N}-\mathrm{C}$ angles are slightly bent with values ranging from $164.4(9)^{\circ}$ to $174.3(5)^{\circ}$.

The DMF molecules in the structure of $\mathbf{1}$ are participating in hydrogen bonds. The $\mathrm{NH}$ group of the uncoordinated benzimidazolyl ring of the bbp ligand is hydrogen-bonded to the oxygen atom of the DMF molecule with $\mathrm{N} \cdots \mathrm{O}$ distances of 2.673-2.767 $\AA$ (Figure 2 and Table S3). In addition, the crystal structure of $\mathbf{1}$ is stabilized by intermolecular $\pi-\pi$ interactions between the benzimidazolyl rings as well as pyridinyl rings of the bbp ligands, as shown in Figure 2. The shortest $\mathrm{Co} \cdots \mathrm{Co}$ distance between $\left[\mathrm{Co}(\mathrm{bbp})_{2}\right]^{2+}$ and $[\mathrm{Co}-$ $\left.(\mathrm{NCS})_{4}\right]^{2-}$ is $8.392(9) \AA$, while the shortest Co $\cdots$ Co distance between the two $\left[\mathrm{Co}(\mathrm{bbp})_{2}\right]^{2+}$ cations is 9.3513(8) $\AA$.

An X-ray structure analysis shows that complex 2 crystallizes in triclinic space group $P \overline{1}$. Its crystal structure consists of a mononuclear neutral $\left[\mathrm{Co}(\mathrm{bbp})(\mathrm{NCS})_{2}(\mathrm{DMF})\right]$ unit and two molecules of crystallized DMF (Figure 3). The overall coordination geometry of 2 is best described as a distorted octahedron with a $\mathrm{CoN}_{5} \mathrm{O}$ environment (Table S2). In the complex, the cobalt center is coordinated to three nitrogen donor atoms of the bbp ligand, two nitrogen donor atoms of two thiocyanate anions, and one oxygen donor atom from a DMF molecule. The trans $\mathrm{N}(1)-\mathrm{Co}-\mathrm{N}(4), \mathrm{N}(3)-\mathrm{Co}-\mathrm{N}(6)$ and $\mathrm{N}(7)-\mathrm{Co}-\mathrm{O}(1)$ angles are 150.5(1), 174.2(1), and $174.3(1)^{\circ}$ respectively, whereas cis $\mathrm{N}-\mathrm{Co}-\mathrm{N}$ and $\mathrm{N}-\mathrm{Co}-\mathrm{O}$

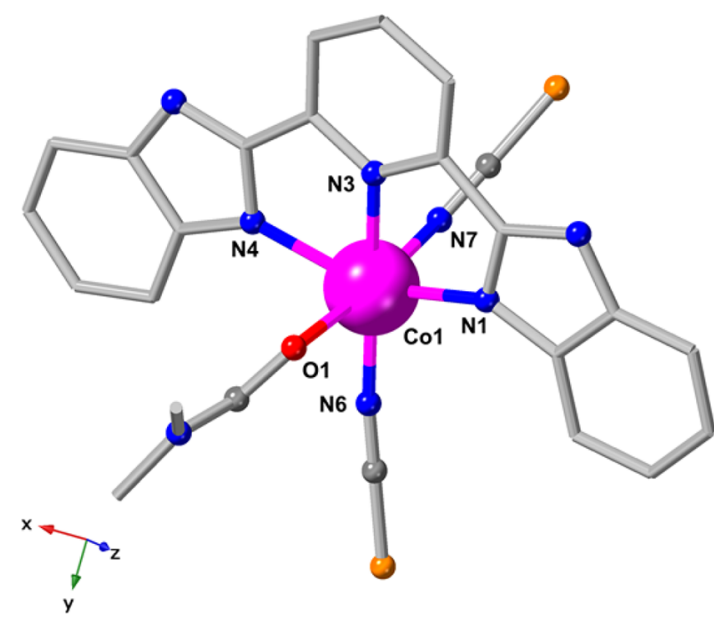

Figure 3. Perspective view of complex 2. Hydrogen atoms and solvent molecules are omitted for clarity ( $\mathrm{Co}$, pink; $\mathrm{C}$, gray; $\mathrm{N}$, blue; $\mathrm{O}$, red; $S$, orange).

angles are in the range of $75.4(1)-106.9(1)^{\circ}$. The Co- $\mathrm{N}_{b b p}$ bonds with an average distance of $2.146 \AA$ are longer than Co$\mathrm{N}_{\mathrm{NCS}}$ bonds with an average value of $2.050 \AA$, while the Co$\mathrm{O}_{\mathrm{DMF}}$ bond distance is $2.272(3) \AA$. These values are similar to the expected HS Co(II) complexes in an octahedral geometry. The coordinated thiocyanate anions are almost linear with $\mathrm{N}-$ $\mathrm{C}-\mathrm{S}$ angles of $178.9(4)\left((\mathrm{N}(7)-\mathrm{C}(20)-\mathrm{S}(1))\right.$ and $179.3(4)^{\circ}$ $(\mathrm{N}(6)-\mathrm{C}(21)-\mathrm{S}(2))$; however, $\mathrm{Co}-\mathrm{N}(6)-\mathrm{C}(21)$ is almost linear with a value of $173.1(4)^{\circ}$ and $\mathrm{Co}-\mathrm{N}(7)-\mathrm{C}(20)$ is significantly bent with a value of $142.8(3)^{\circ}$.

In the complex 2, the DMF molecules form $\mathrm{N}-\mathrm{H} \cdots \mathrm{O}$ hydrogen bonds with the $\mathrm{NH}$ groups of the benzimidazolyl ring of the bbp ligand with $\mathrm{N} \cdots \mathrm{O}$ distances of 2.746(5) and $2.712(5) \AA$ and $\mathrm{N}-\mathrm{H} \cdots \mathrm{O}$ angles of 176.15 and $178.29^{\circ}$ (Figure 4). Moreover, the crystal structure of 2 is stabilized by intermolecular $\pi-\pi$ interactions between pyridinyl rings of the bbp ligands and intermolecular $\mathrm{C}-\mathrm{H} \cdots \mathrm{N}$ and $\mathrm{C}-\mathrm{H} \cdots \mathrm{C}$ interactions, as shown in Figure 4. Short intra- and intermolecular contacts are collected in Table S3. The shortest Co $\cdots$ Co distance between two $\left[\mathrm{Co}(\mathrm{bbp})(\mathrm{NCS})_{2}(\mathrm{DMF})\right]$ units is $8.556(1) \AA$.

Complex 3 crystallizes in triclinic space group $P \overline{1}$. Its crystal structure consists of a mononuclear neutral $\left[\mathrm{Co}(\mathrm{bbp})(\mathrm{NCS})_{2}\right]$ 

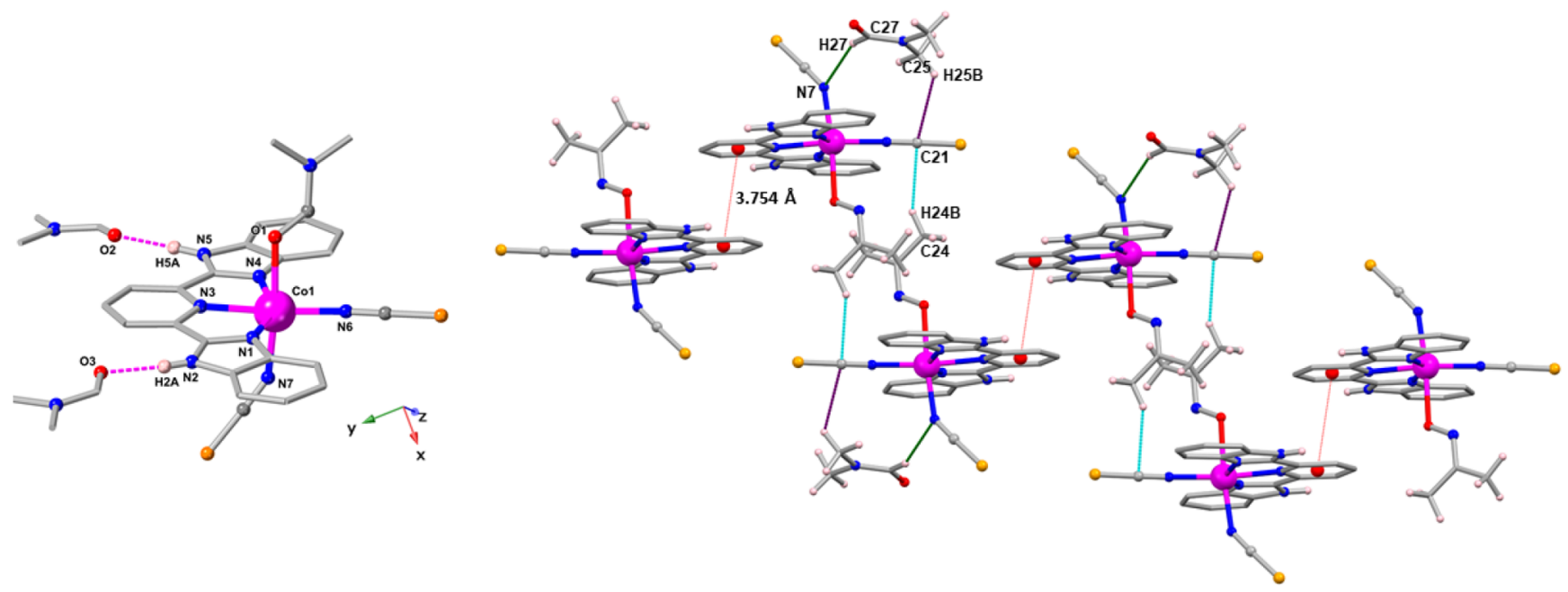

Figure 4. Perspective views of the molecular structure of 2 displaying $\mathrm{N}-\mathrm{H} \cdots \mathrm{O}$ hydrogen bonds (violet dotted lines) (left) and the fragment of the supramolecular structure formed by weak intermolecular $\pi \cdots \pi$ (red dotted lines), $\mathrm{C}-\mathrm{H} \cdots \mathrm{N}$ (green dotted lines), and $\mathrm{C}-\mathrm{H} \cdots \mathrm{C}$ (cyan and purple dotted lines) interactions (right).

unit (Figure 5). The overall coordination geometry of 3 is best described as a distorted square pyramid with a $\mathrm{CoN}_{5}$

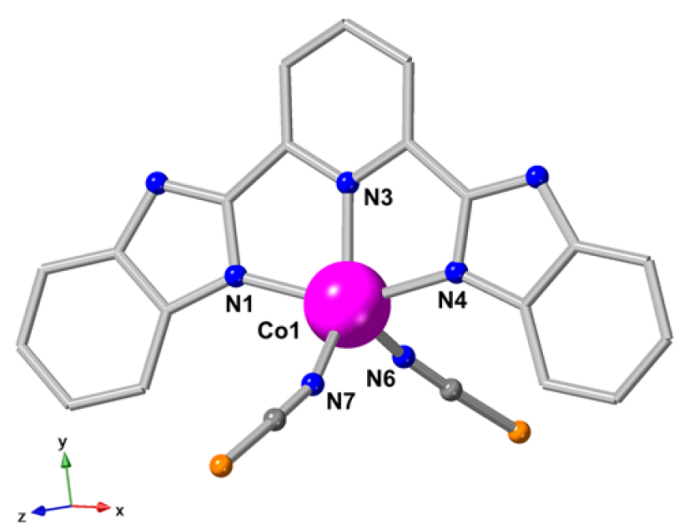

Figure 5. Perspective view of complex 3. Hydrogen atoms and solvent molecules are omitted for clarity (Co, pink; C, gray; N, blue; S, orange).

environment (Table S2), where the cobalt center is coordinated by three nitrogen donor atoms of the bbp ligand and two nitrogen donor atoms of the two thiocyanate ligands. The nitrogen atoms of the bbp ligand and one of the thiocyanate nitrogen atoms occupy equatorial positions with two trans-positioned $\mathrm{N}-\mathrm{Co}-\mathrm{N}$ angles of $151.3(1)^{\circ}$ for $\left(\mathrm{N}(1)-\mathrm{Co}-\mathrm{N}(4)\right.$ and $134.3(1)^{\circ}$ for $\mathrm{N}(3)-\mathrm{Co}-\mathrm{N}(7)$, while the other thiocyanate nitrogen atom occupies an apical position. These angles deviate significantly from the ideal values in an perfect square-pyramidal geometry, and thus the coordination geometry in 3 can be classified using the Addison parameter $(\tau)$ to be closer to square pyramidal $(\tau=0.28$, where $\tau=0$ for ideal square pyramidal and $\tau=1$ for ideal trigonal bipyramidal). ${ }^{52}$ In the complex, the average Co-N bond length of $2.067 \AA$ indicates a HS state of the central $\mathrm{Co}(\mathrm{II})$ atom. The coordinated thiocyanate anions are almost linear with $\mathrm{N}-\mathrm{C}-\mathrm{S}$ angles of $177.8(2)$ and $177.2(3)^{\circ}$; however, the $\mathrm{Co}-\mathrm{N}-\mathrm{C}$ angles are $161.9(3)$ and $162.6(3)^{\circ}$. In addition, the complex molecules are assembled in supramolecular chains by $\mathrm{N}-\mathrm{H} \cdots \mathrm{S}$ intermolecular hydrogen bonds between the sulfur atom of a thiocyanate anion and an uncoordinated nitrogen atom of the bbp ligand with $\mathrm{N} \cdots \mathrm{S}$ distances of 3.313(2) and 3.271(2) A (Figure S5 and Table S3).

Magnetic Studies. The temperature dependence of $\chi T(\chi$ is the magnetic susceptibility, equal to $M / H$ per two $\mathrm{Co}^{\mathrm{II}}$ ions) was studied on 1 in the temperature range of $2-300 \mathrm{~K}$ at 2500 Oe (Figure 6). At $300 \mathrm{~K}$, the measured $\chi T$ value is $4.5 \mathrm{~cm}^{3}$

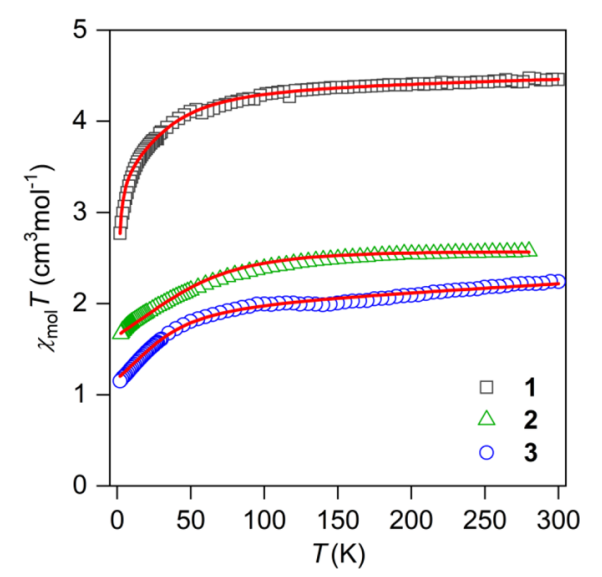

Figure 6. Temperature dependence of $\chi T$ for 1-3. The empty symbols denote experimental data and full lines calculated data with the parameters in the text.

$\mathrm{mol}^{-1} \mathrm{~K}$, which lies in the expected range for two $\mathrm{HS} \mathrm{d}^{7} \mathrm{Co}^{\mathrm{II}}$ ions $\left(S=2 \times 3 / 2, g=2.0 ; \chi T=2 \times 1.875 \mathrm{~cm}^{3} \mathrm{~mol}^{-1} \mathrm{~K}\right)$ (contribution from one pseudo-octahedral and another tetrahedral $\mathrm{Co}(\mathrm{II})$ coordination polyhedron). ${ }^{53-58}$ The $\chi T$ value decreases gradually with a decrease in the temperature to reach a value of $4.1 \mathrm{~cm}^{3} \mathrm{~mol}^{-1} \mathrm{~K}$ at $50 \mathrm{~K}$ and then decreases abruptly, reaching a minimum of $2.6 \mathrm{~cm}^{3} \mathrm{~mol}^{-1} \mathrm{~K}$ at $2 \mathrm{~K}$. In addition, $\mathrm{Co}(\mathrm{II})$ complexes in a similar type of $\mathrm{Co}(\mathrm{N} 3)_{2}$ coordination environment exhibit spin crossover behavior depending on the appropriate ligand field. ${ }^{59-63}$ However, for complex 1, we have not observed any such property in the measured temperature range from 2 to $300 \mathrm{~K}$, which is also confirmed by DSC measurements (Figure S30). 
Table 2. Ab Initio Calculated and Fitted Spin Hamiltonian Parameters for Compounds 1-3

\begin{tabular}{|c|c|c|c|c|}
\hline & {$\left[\mathrm{Co}(\mathrm{bbp})_{2}\right]^{2+}$ of $\mathbf{1}$} & {$\left[\mathrm{Co}(\mathrm{NCS})_{4}\right]^{2-}$ of $\mathbf{1}$} & {$\left[\mathrm{Co}(\mathrm{bbp})(\mathrm{NCS})_{2}(\mathrm{DMF})\right]$ of $\mathbf{2}$} & {$\left[\mathrm{Co}(\mathrm{bbp})(\mathrm{NCS})_{2}\right]$ of 3} \\
\hline \multicolumn{5}{|c|}{ ZFS and $g$ Values Based on CASSCF/NEVPT2 Calculations } \\
\hline$D\left(\mathrm{~cm}^{-1}\right)$ & 46.7 & -1.23 & 96.6 & 39.4 \\
\hline$E / D$ & 0.093 & 0.209 & 0.274 & 0.137 \\
\hline$g_{x}$ & 2.429 & 2.230 & 2.223 & 2.364 \\
\hline$g_{y}$ & 2.569 & 2.224 & 2.962 & 2.477 \\
\hline$g_{z}$ & 2.051 & 2.241 & 1.900 & 2.041 \\
\hline \multicolumn{5}{|c|}{ ZFS Values Based on CASSCF/DCD-CAS(2) Calculations } \\
\hline$D\left(\mathrm{~cm}^{-1}\right)$ & 49.0 & -1.32 & 99.3 & 41.0 \\
\hline$E / D$ & 0.093 & 0.211 & 0.278 & 0.113 \\
\hline \multicolumn{5}{|c|}{ Magnetic Analysis of the Experimental Data } \\
\hline$D\left(\mathrm{~cm}^{-1}\right)$ & 39.0 & 0.0 & 69.5 & 38.1 \\
\hline$E / D$ & 0.09 & 0.0 & 0.12 & 0.0 \\
\hline$g_{\text {iso }}$ & 2.16 & 2.16 & $g_{x y}=2.46, g_{z}=2.00$ & 2.04 \\
\hline
\end{tabular}

The magnetic properties of $\mathbf{2}$ were investigated by measuring the temperature dependence of $\chi T$ in the temperature range of $2.5-280 \mathrm{~K}$ at $1000 \mathrm{Oe}$ (Figure 6). The measured $\chi T$ value at $280 \mathrm{~K}$ is $2.57 \mathrm{~cm}^{3} \mathrm{~mol}^{-1} \mathrm{~K}$, which is significantly larger than the spin-only value for one $\mathrm{HS} \mathrm{d}^{7} \mathrm{Co}^{\mathrm{II}}$ ion $\left(S=3 / 2, g=2.0 ; \chi^{T}=1.875 \mathrm{~cm}^{3} \mathrm{~mol}^{-1} \mathrm{~K}\right)$, indicating the presence of an orbital angular momentum contribution. ${ }^{53-58}$ Upon a decrease in the temperature, the $\chi T$ value decreases slowly to reach a value of $2.39 \mathrm{~cm}^{3} \mathrm{~mol}^{-1} \mathrm{~K}$ at $100 \mathrm{~K}$. On a further decrease in temperature, the $\chi T$ value decreases abruptly to a value of $1.68 \mathrm{~cm}^{3} \mathrm{~mol}^{-1} \mathrm{~K}$ at $2.5 \mathrm{~K}$. DSC measurements confirm the absence of phase transition at the measured temperature range from 295 to $130 \mathrm{~K}$ (Figure S31) and thus the absence of spin crossover properties.

Magnetic investigations of 3 were carried out by measuring the temperature dependence of $\chi T$ in the temperature range of $2-300 \mathrm{~K}$ at 1000 Oe (Figure 6). The measured $\chi T$ value at $300 \mathrm{~K}$ is $2.21 \mathrm{~cm}^{3} \mathrm{~mol}^{-1} \mathrm{~K}$, which is slightly larger than the spin-only value for one $\mathrm{HS} \mathrm{d}^{7} \mathrm{Co}^{\mathrm{II}}$ ion $(S=3 / 2, g=2.0 ; \chi \mathrm{T}=$ $\left.1.875 \mathrm{~cm}^{3} \mathrm{~mol}^{-1} \mathrm{~K}\right)$, suggesting the presence of an orbital angular momentum contribution. ${ }^{53-58}$ The $\chi T$ value decreases gradually with a decrease in the temperature to reach a value of $1.97 \mathrm{~cm}^{3} \mathrm{~mol}^{-1} \mathrm{~K}$ at $90 \mathrm{~K}$ and then decreases abruptly, reaching a minimum of $1.14 \mathrm{~cm}^{3} \mathrm{~mol}^{-1} \mathrm{~K}$ at $2 \mathrm{~K}$.

In all complexes 1-3, the decrease in $\chi T$ value at low temperature is probably due to the combined effect of the magnetic anisotropy and spin-orbit coupling coming from a $\mathrm{HS} \mathrm{Co}(\mathrm{II})$ ion and also to the weak antiferromagnetic intermolecular interactions.

In the case of compound $\mathbf{1}$, there are two distinct paramagnetic centers and the spin Hamiltonian was formulated as

$$
\begin{aligned}
\hat{H}= & \sum_{i=1}^{2} D_{i}\left(\hat{S}_{z, i}^{2}-\hat{S}_{i}^{2} / 3\right)+E_{i}\left(\hat{S}_{x, i}^{2}-\hat{S}_{y, i}^{2}\right)+\mu_{\mathrm{B}} B g_{i} \hat{S}_{a, i} \\
& -z j\left\langle\hat{S}_{a}\right\rangle \hat{S}_{a}
\end{aligned}
$$

and incorporates the single-ion axial $(D)$ and the single-ion rhombic ( $E$ ) ZFS parameters, the Zeeman term defined for a direction of the magnetic field as $B_{a}=B(\sin \theta \cos \varphi, \sin \theta \sin$ $\varphi, \cos \theta)$ using the spherical coordinates and also $z j$, the molecular field correction. Next, the molar magnetization for any $a$ direction of the magnetic field $\left(M_{a}\right)$ was computed by the formula

$$
M_{a}=-N_{\mathrm{A}} \frac{\sum_{i}\left(\sum_{k} \sum_{l} C_{i k}^{+}\left(Z_{a}\right)_{k l} C_{l i}\right) \exp \left(-\varepsilon_{a, i} / k T\right)}{\sum_{i} \exp \left(-\varepsilon_{a, i} / k T\right)}
$$

in which the matrix elements of the Zeeman term $\left(Z_{a}\right)$ and the eigenvectors $(C)$ of the complete spin Hamiltonian matrix computed along the $a$ direction of the magnetic field are exploited. Moreover, the occurrence of a molecular field correction implies that the iterative technique must be employed. ${ }^{64}$ Finally, an integral averaging was applied to compute the powder average of the molar magnetization using eq 3 .

$$
M_{\text {mol }}=\frac{1}{4 \pi} \int_{0}^{2 \pi} \int_{0}^{\pi} M_{a} \sin \theta \mathrm{d} \theta \mathrm{d} \phi
$$

According to the theoretical CASSCF/NEVPT2 calculations (vide infra), the $D$ parameter of the $\left[\mathrm{Co}(\mathrm{NCS})_{4}\right]^{2-}$ complex anion of $\mathbf{1}$ should be negligibly small in comparison with the value of $D$ for the $\left[\mathrm{Co}(\mathrm{bbp})_{2}\right]^{2+}$ complex cation (Table 2). Therefore, $D_{\text {anion }}$ was fixed to zero to prevent overparametrization of the model. As a result, the best-fit parameters were found to be $D_{\text {cation }}=39.0 \mathrm{~cm}^{-1}, E / D=0.09, g=2.16$, and $\chi_{\text {TIP }}$ $=3.8 \times 10^{-4} \mathrm{~cm}^{3} \mathrm{~mol}^{-1}$ with $z j=-0.18 \mathrm{~cm}^{-1}$, where $\chi_{\text {TIP }}$ stands for the temperature-independent paramagnetism (Figure 6).

Next, the experimental magnetic data of $\mathbf{2}$ were treated with a spin Hamiltonian for the mononuclear system with zero-field splitting

$$
\hat{H}=D\left(\hat{S}_{z}^{2}-\hat{S}^{2} / 3\right)+E\left(\hat{S}_{x}^{2}-\hat{S}_{y}^{2}\right)+\mu_{\mathrm{B}} B g \hat{S}_{a}
$$

which resulted in $D=69.5 \mathrm{~cm}^{-1}, E / D=0.12$, and $g_{x y}=2.46$ with the fixed parameter $g_{z}=2.00$ (Figure 6). However, the theoretical calculations for this complex suggests that there are low-lying excited states (vide infra), which makes the application of the spin Hamiltonian formalism questionable. The ${ }^{4} \mathrm{~F}$ atomic term fragments into the ${ }^{4} \mathrm{~T}_{1 \mathrm{~g}}$ ground state and excited ${ }^{4} \mathrm{~T}_{2 \mathrm{~g}}$ and ${ }^{4} \mathrm{~A}_{2 \mathrm{~g}}$ states upon formation of $\mathrm{Co}$ (II) (pseudo)octahedral complexes. Thus, the ground state possesses an unquenched orbital angular momentum and the formalism of the spin Hamiltonian is forbidden. ${ }^{65,66}$ Such a situation was treated by Griffith and Figgis, ${ }^{67,68}$ who described the splitting of energy levels arising from the ${ }^{4} \mathrm{~T}_{1 \mathrm{~g}}$ state with the L-S Hamiltonian using this equation 


$$
\begin{aligned}
\hat{H}= & -\alpha \cdot \lambda(\vec{S} \cdot \vec{L})+\Delta_{\mathrm{ax}}\left(\hat{L}_{z}^{2}-\hat{L}^{2} / 3\right)+\Delta_{\mathrm{rh}}\left(\hat{L}_{x}^{2}-\hat{L}_{y}^{2}\right) \\
& +\mu_{\mathrm{B}} \vec{B}\left(g_{\mathrm{e}} \vec{S}-\alpha \vec{L}\right)
\end{aligned}
$$

where the parameters $\Delta_{\mathrm{ax}}$ and $\Delta_{\mathrm{rh}}$ measure splitting of the ${ }^{4} \mathrm{~T}_{1 \mathrm{~g}}$ ground term produced by lowering of the symmetry, $\alpha$ is an orbital reduction factor, $\lambda$ is the spin-orbit coupling, and $g_{\mathrm{e}}$ is the free-electron $g$ factor (2.0023). This Hamiltonian exploits $\mathrm{T}_{1}-\mathrm{P}$ isomorphism; consequently, the angular orbital momentum $L$ is equal to 1 with the effective Lande $g$ factor $g_{\mathrm{L}}=-\alpha$ and is applied to $\left|S, L, M_{S}, M_{L}\right\rangle$ functions with $M_{L}=0, \pm 1$ and $M_{S}= \pm 1 / 2, \pm 3 / 2{ }^{69}$ The orbital reduction factor $\alpha$ equals $A \kappa$; thus, it assimilates two parameters, namely $A$, which is the Figgis coefficient of the configuration interaction resulting from the admixture of the excited terms reflecting the ligand field strength $(1<A<3 / 2)$, and $\kappa$ defines the lowering orbital contribution caused by covalency of the metal-ligand bond and is typically in the range $0.70<\kappa<1$. Furthermore, the spin-orbit coupling parameter $\lambda$ can be also reduced in comparison with its free-ion value $\lambda_{0}=-180 \mathrm{~cm}^{-1}$ due to the covalent character of the donor-acceptor bond. Thus, the magnetic data of $\mathbf{2}$ were also treated with the L-S Hamiltonian (eq 5), which resulted in the following parameters: $\alpha=0.93, \lambda$ $=-172 \mathrm{~cm}^{-1}, \Delta_{\mathrm{ax}}=-733 \mathrm{~cm}^{-1}, \Delta_{\mathrm{rh}}=-105 \mathrm{~cm}^{-1}$ (Figure S36). These parameters are in accordance with the parameters obtained from the evaluation of CASSCF/NEVPT2 calculations (vide infra).

The last complex 3 was again analyzed with the spin Hamiltonian in eq 4, and the best fit was obtained with $D=$ $38.1 \mathrm{~cm}^{-1}, E / D=0.0, g=2.04$, and $\chi_{\text {TIP }}=9.0 \times 10^{-4} \mathrm{~cm}^{3}$ $\mathrm{mol}^{-1}$, confirming the large magnetic anisotropy of this complex.

The field dependence of magnetization studies for 1 was carried out from 0 to $7 \mathrm{~T}$ at 3 and $5 \mathrm{~K}$ (Figure 7 and Figure
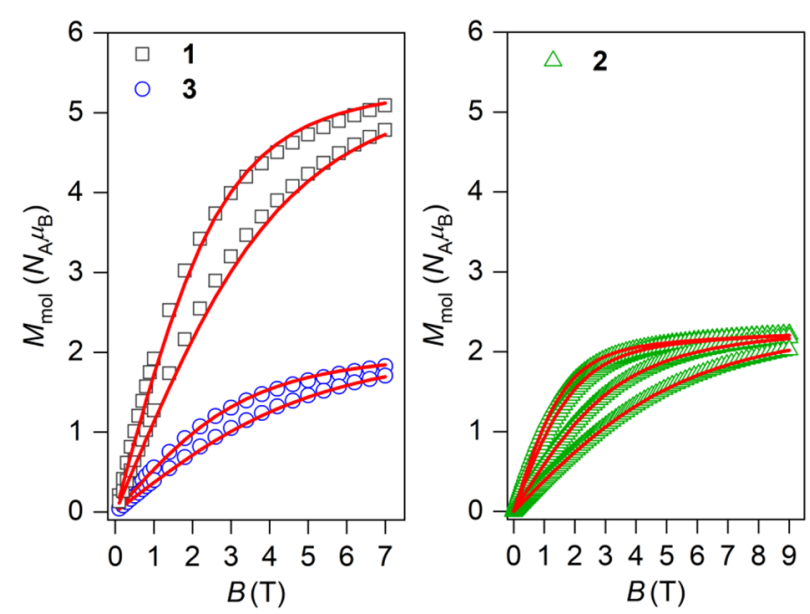

Figure 7. Field dependence of the magnetization as $M$ vs $B$ plots of 1-3. The empty symbols denote experimental data and the full lines calculated data with the parameters in the text.

S15). At $3 \mathrm{~K}$ and $7 \mathrm{~T}$, the magnetization value is $5.38 \mu_{\mathrm{B}}$, which is slightly lower than the expected value for two $S=3 / 2$ systems. In addition, $M$ vs $H / T$ measurements display nonsuperposition of the data on a single master curve (Figure S15), suggesting the presence of magnetic anisotropy in this system. The field-dependent magnetization measurements for 2 were performed from 0 to $9 \mathrm{~T}$ at 2.5, 3, 5, and $8 \mathrm{~K}$ (Figure 7 and Figure S16). The magnetization value at $2.5 \mathrm{~K}$ and $9 \mathrm{~T}$ is
$2.22 \mu_{\mathrm{B}}$, which is lower than the expected value of an $S=3 / 2$ system. Moreover, $M$ vs $H / T$ measurements show nonsuperposition of the data on a single master curve (Figure S16). The nonsaturation and nonsuperposition of the magnetization curves suggest the presence of magnetic anisotropy and/or low-lying excited states. The field dependence of magnetization studies for 3 was performed from 0 to 7 $\mathrm{T}$ at 4 and $6 \mathrm{~K}$ (Figure 7 and Figure S17). At $4 \mathrm{~K}$ and $7 \mathrm{~T}$, the magnetization value is $1.82 \mu_{\mathrm{B}}$, which is lower than the expected value of a $S=3 / 2$ system. $M$ vs $H / T$ measurements display nonsuperposition of the data on a single master curve (Figure. S17). $M$ vs $H$ and $M$ vs $H / T$ curves suggest the presence of magnetic anisotropy. No hysteresis was observed in $M$ vs $H$ at $2 \mathrm{~K}$ from -70000 to +70000 Oe with a sweep rate of 100-600 Oe (Figure S18).

In order to understand the slow dynamics of magnetization, ac susceptibility measurements were carried out on $1-3$. The real $\left(\chi^{\prime}\right)$ and imaginary $\left(\chi^{\prime \prime}\right)$ components of the ac susceptibility under zero dc field were measured at low temperature at driving frequencies up to $1500 \mathrm{~Hz}$ (for $\mathbf{1}$ and 3) and $10000 \mathrm{~Hz}$ (for 2) (Figure 8 and , Figures S19-S21). No out-of-phase $\chi^{\prime \prime}$ signal under zero dc field was observed for any of the three complexes, indicating that effective quantum tunneling of magnetization (QTM) occurred at zero dc field.

It was demonstrated that the external magnetic field strongly affected the QTM. Thus, in order to minimize the probability of the quantum relaxation pathway in zero dc field and to estimate the energy barrier accurately, the ac susceptibility was measured under different dc fields. It is worth mentioning that no slow relaxation of magnetization was detected in the case of complex $\mathbf{1}$ from ac susceptibility measurements even by using a 6000 Oe dc magnetic field (Figure S21), although slow relaxation of magnetization has recently been reported in $\left[\mathrm{Co}(\mathrm{N} 3)_{2}\right]\left[\mathrm{Co}(\mathrm{NCS})_{4}\right](\mathrm{N} 3=$ tridentate $\mathrm{N}$-donor ligand $)$ types of complexes as well as in the $\left[\mathrm{Co}(\mathrm{NCS})_{4}\right]^{2-}$ unit with different metal cation complexes. ${ }^{70-73}$

For complex 2, the dynamics of the magnetization was studied under different applied dc fields up to $10000 \mathrm{Oe}$ at $2 \mathrm{~K}$ to reduce the possibility of a quantum relaxation pathway (Figure 8). A generalized Debye model ${ }^{74}$ was employed to fit $\chi^{\prime}$ vs $\nu$ and $\chi^{\prime \prime}$ vs $\nu$ to obtain the characteristic frequency of relaxation (Figure S22). A plot of the characteristic frequency (maxima of $\chi^{\prime \prime}$ vs $\nu$ plot) vs applied different dc fields gives an optimum dc field of $1000 \mathrm{Oe}$, where the dynamics is the slowest (Figure S23).

Accordingly, ac susceptibility measurements were performed using a 1000 Oe external dc field at different temperatures and ac frequencies (Figure 9).

A clear maximum is detected in the $\chi^{\prime \prime}$ vs $\nu$ plot at $1000 \mathrm{Oe}$, allowing us to deduce the relaxation time. A linear fit of the experimental $\tau$ vs $1 / T$ plot using the Arrhenius equation allows an estimation of the energy barrier $\Delta_{\text {eff }} / k_{\mathrm{B}}=35.4 \mathrm{~K}$ and the pre-exponential factor $\tau_{0}=4.03 \times 10^{-8} \mathrm{~s}$ (Figure 10). Moreover, the whole temperature dependence of the relation times was fitted to a combination of direct, Raman, and Orbach relaxation processes using

$$
\frac{1}{\tau}=A T+C T^{n}+\frac{1}{\tau_{0}} \exp \left(-\frac{\Delta_{\text {eff }}}{k T}\right)
$$

which resulted in $A=128 \mathrm{~K}^{-1} \mathrm{~s}^{-1}, C=39.4 \mathrm{~K}^{-n} \mathrm{~s}^{-1}, n=4.01$, $\tau_{0}=8.59 \times 10^{-9} \mathrm{~s}^{-1}$, and $\Delta_{\text {eff }}=53.2 \mathrm{~K}$ (Figure 10). Alternatively, the only slightly poor fit was achieved by the 

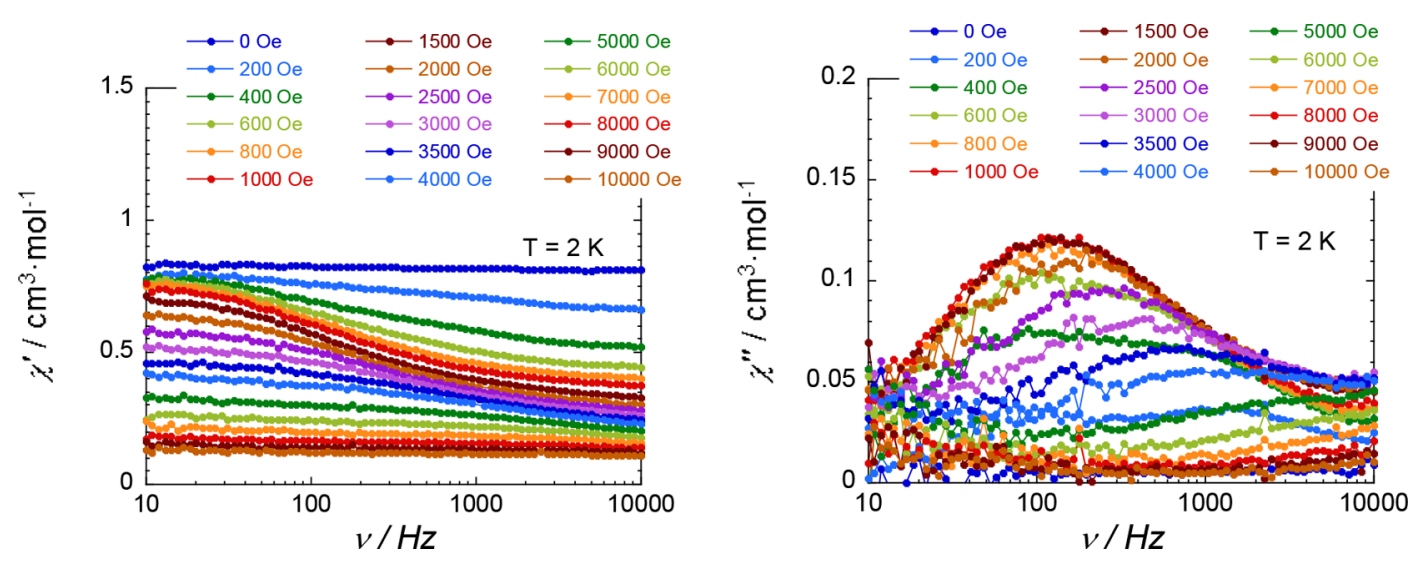

Figure 8. Frequency dependence of the real $\left(\chi^{\prime}\right.$, left $)$ and imaginary $\left(\chi^{\prime \prime}\right.$, right $)$ components of the ac susceptibility at different ac frequencies from 1 to $10000 \mathrm{~Hz}$ and different external dc field from 10 to $10000 \mathrm{Oe}$, respectively, with a $3 \mathrm{Oe}$ ac field for 2 at $2 \mathrm{~K}$.
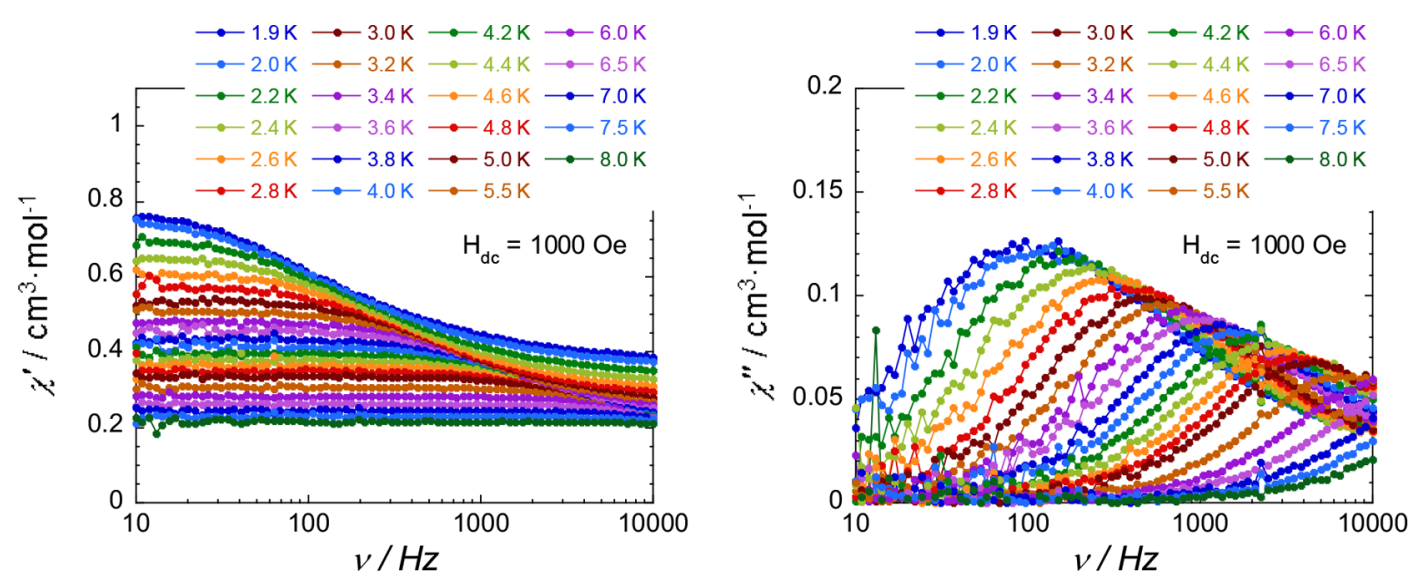

Figure 9. Frequency dependence of the real $\left(\chi^{\prime}\right.$, left $)$ and imaginary $\left(\chi^{\prime \prime}\right.$, right $)$ components of the ac susceptibility at different ac frequencies from 10 to $10000 \mathrm{~Hz}$ under a 1000 Oe external dc field, with a 3 Oe ac field for 2 at $2 \mathrm{~K}$.

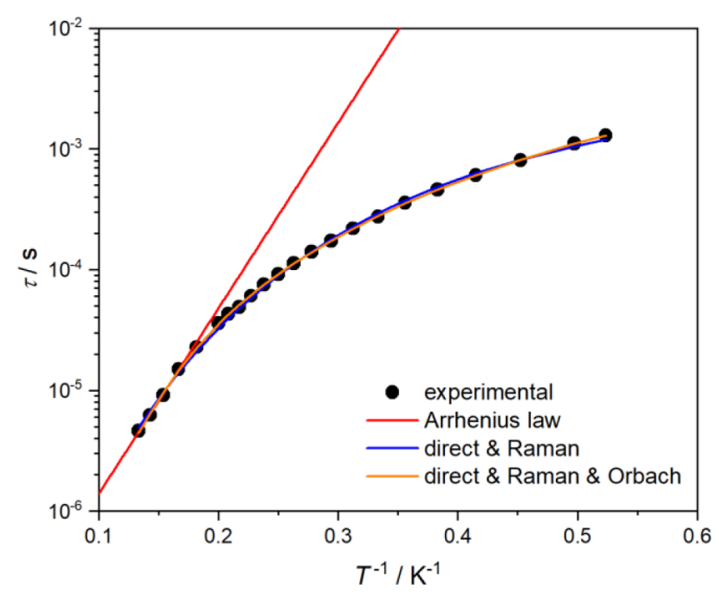

Figure 10. Temperature dependence of the magnetization relaxation time as $\tau$ versus $T^{-1}$ plot for 2 in a 1000 Oe dc field. The full lines correspond to various combinations of the relaxation processes as described in the text.

combination of direct and Raman relaxation processes with $A$ $=284 \mathrm{~K}^{-1} \mathrm{~s}^{-1}, C=13.6 \mathrm{~K}^{-n} \mathrm{~s}^{-1}$, and $n=4.77$ (Figure 10), suggesting that at such low temperatures the first excited Kramers doublet is high in energy and thus its low Boltzmann population makes the Orbach relaxation pathway inefficient.

The Cole-Cole plots were fitted using a generalized Debye model (Figure S24 and Table S4); details of this fitting are given in the Supporting Information. From the Cole-Cole plots, we obtained different values of $\alpha$, which lie in the range of $0.04-0.36$, suggesting a narrow distribution of the relaxation times $(\tau)$ (Figure S25).

Under an applied dc field, complex 3 shows frequencydependent signals in both components of the ac susceptibility, which suggest the slow relaxation of the magnetization. Similar to the case for complex 2, ac susceptibility measurements were carried out at different applied dc fields up to $6000 \mathrm{Oe}$ at $1.8 \mathrm{~K}$ (Figure S26). From the ac measurements and the field variation of the characteristic frequency (Figure S27), quantum effects are evidently minimized around $1500 \mathrm{Oe}$, as displayed by the minimum of the characteristic frequency at this dc field. Therefore, ac susceptibility measurements were carried out under 1500 Oe external dc field at different temperatures and ac frequencies (Figure 11 and Figure S28) to calculate the temperature dependence of the relaxation time.

A relaxation mode is detected on $\chi^{\prime \prime}$ vs $\nu$ data. From the ac data (Figure 11), an Arrhenius plot was produced, as shown in Figure 12. The relaxation shows a thermally activated behavior with the energy barrier $\Delta_{\text {eff }} / k_{\mathrm{B}}=6.9 \mathrm{~K}$ and the pre-exponential factor $\tau_{0}=1.8 \times 10^{-5} \mathrm{~s}$. From the Cole-Cole plots, we obtained different values of $\alpha$, which are in the range of $0.03-$ 0.41 , also indicating a narrow distribution of the relaxation times $(\tau)$ (Figure S29 and Table S5).

Very recently $\mathrm{Mondal}^{75}$ et al. reported the magnetic properties of the similar complex $\left[\left(\mathrm{Co}(\mathrm{bbp})(\mathrm{NCS})_{2}\right]\right.$, where 

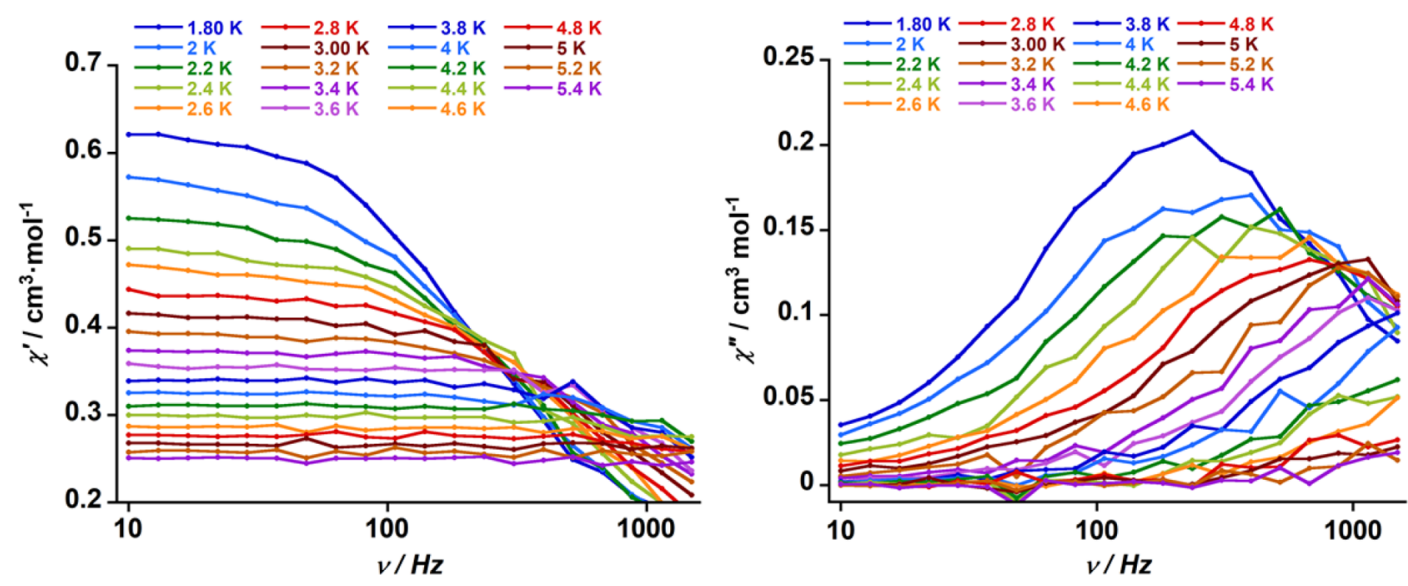

Figure 11. Frequency dependence of the real $\left(\chi^{\prime}\right.$, top) and imaginary $\left(\chi^{\prime \prime}\right.$, bottom) components of the ac susceptibility at different ac frequencies from 1 to $1500 \mathrm{~Hz}$ and different temperatures from 1.8 to $5.4 \mathrm{~K}$, respectively, with a $3 \mathrm{Oe}$ ac field for 3 at 1500 Oe external dc field.

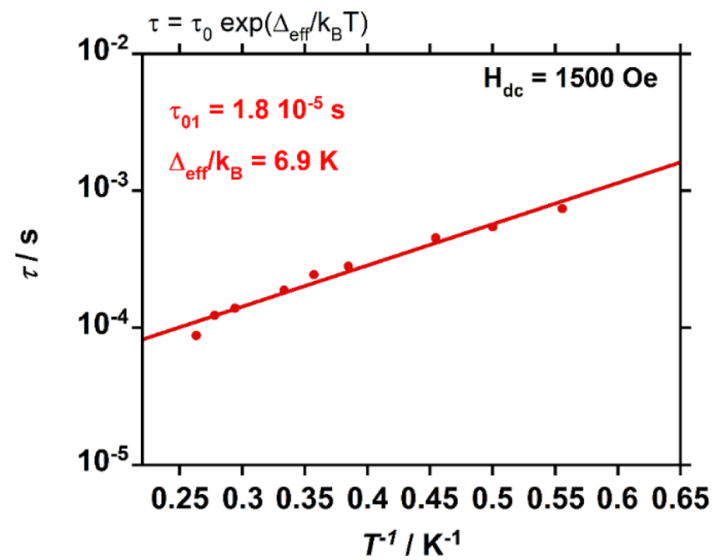

Figure 12. Temperature dependence of the magnetization relaxation time as $\tau$ versus $T^{-1}$ plot for 3 in 1500 Oe dc field.

they demonstrated the magnetic anisotropic parameter $D$ to be $10.7(4) \mathrm{cm}^{-1}$, which is significantly lower than the expected value of around $30-70 \mathrm{~cm}^{-1}$ for $\mathrm{Co}$ (II) with a squarepyramidal coordination geometry. ${ }^{76}$ The authors further reported an effective energy barrier of $9.7 \mathrm{~K}$ and a relaxation time of $4.6 \times 10^{-5} \mathrm{~s}$ under a static magnetic field of 1000 Oe. Indeed, the analysis reported herein ended with $D \approx 40 \mathrm{~cm}^{-1}$ and the results are also supported by CASSCF/NEVPT2 calculations (Table 2). In addition, the analysis reported herein also ended up with the optimization of the applied dc field of $1500 \mathrm{Oe}$ as well as the deduction of an effective energy barrier of $6.9 \mathrm{~K}$ and a relaxation time of $1.8 \times 10^{-5} \mathrm{~s}$ under the optimized applied dc field.

$\mathrm{X}$-band EPR experiments were performed on powdered samples of 1 and 3 in the temperature range of 5-50 K (Figure 13). The signal intensity for both complexes decreases with an increase in the temperature, which indicates the presence of a positive $D$ value. Simulation of the spectra of 1 and 3 at $5 \mathrm{~K}$ are given in Figures S33 and S34 in the Supporting Information.

Theoretical Calculations. In order to get a better insight into the electronic structure and ZFS parameters, theoretical calculations on the complexes extracted from the experimental $\mathrm{X}$-ray structures of 1-3 were applied for the $a b$ initio, DFT, and semiempirical SCF-MO package ORCA 4.1. First, the post-Hartree-Fock multireference calculations built on the state-averaged complete active space self-consistent field
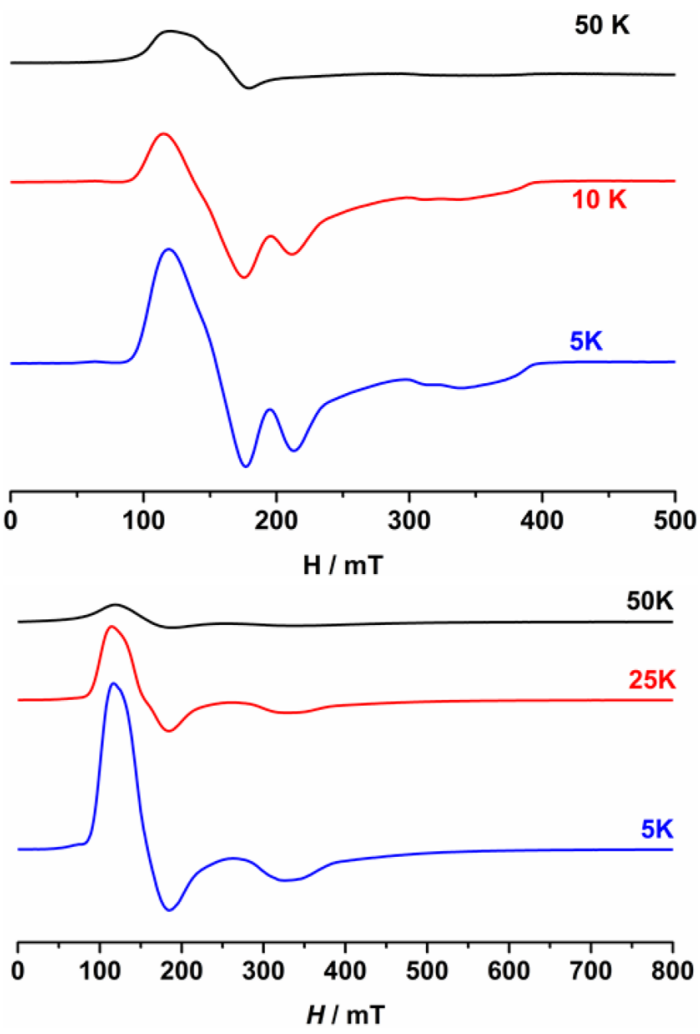

Figure 13. Variable-temperature X-band EPR spectra of the polycrystalline powder of $\mathbf{1}$ (top) and $\mathbf{3}$ (bottom).

method (SA-CASSCF) were accomplished using the def2TZVP basis set. Such calculations resulted in the spin Hamiltonian parameters: particularly, the zero-field splitting parameters $D$ and $E$. Due to the $3 \mathrm{~d}^{7}$ electronic configuration of $\mathrm{Co}^{\mathrm{II}}$ ions, the active space $\mathrm{CAS}(7,5)$ was defined by seven electrons in five d orbitals. In addition to the standard $\mathrm{N}$ electron valence state perturbation theory (NEVPT) used, we have exploited dynamic correlation dressed CAS with the second-order treatment (DCD-CAS(2)) to treat dynamic electron correlation effects. For the calculations of the energy of the $\mathrm{d}$ orbitals, $a b$ initio ligand field theory (AILFT) was applied (Figure 14). The increasing coordination number from four to six is reflected in increasing overall splitting of $d$ orbitals from the tetracoordinate $\left[\mathrm{Co}(\mathrm{NCS})_{4}\right]^{2-}$ complex of 1 through 


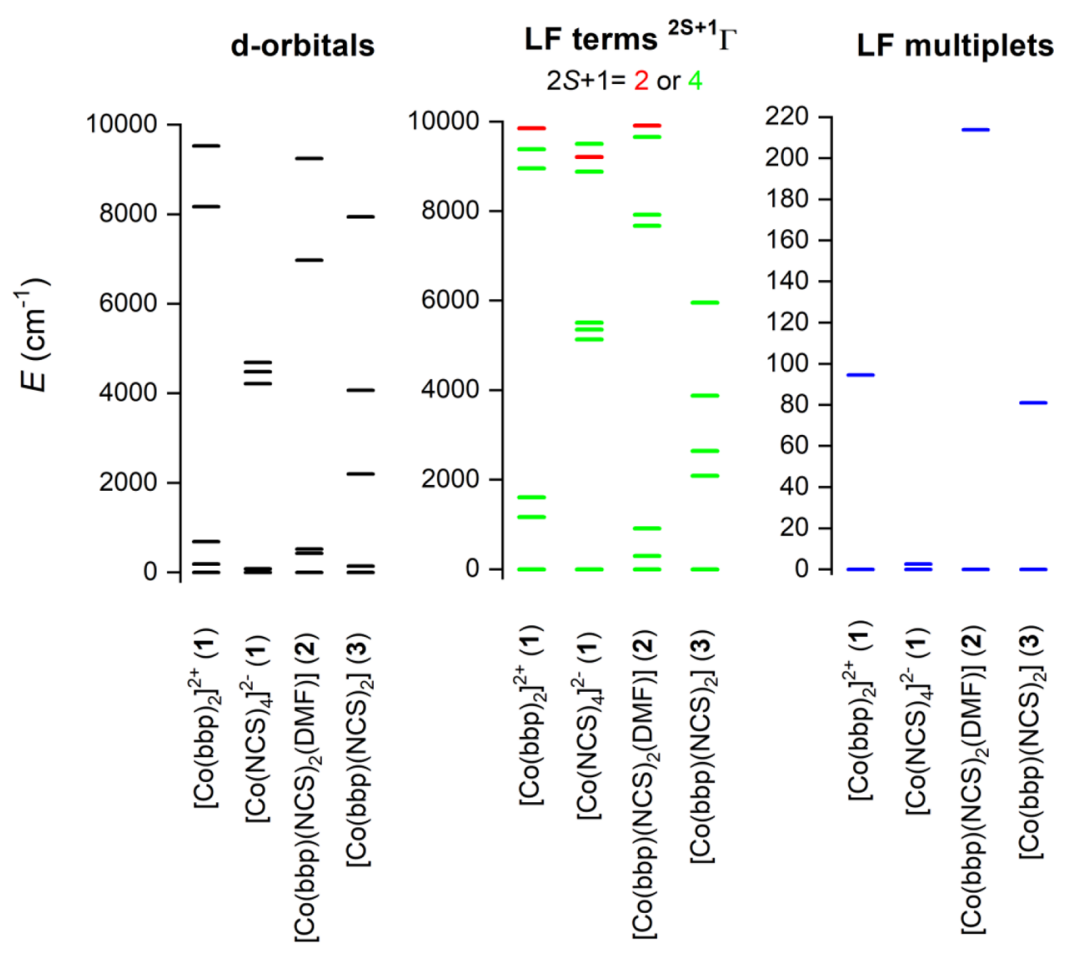

Figure 14. Graphical representation of the CASSCF/NEVPT with CAS $(7,5)$ calculations for the molecular fragments $\left[\mathrm{Co}(\mathrm{bbp})_{2}\right]^{2+}$ and $\left[\mathrm{Co}(\mathrm{NCS})_{4}\right]^{2-}$ of $\mathbf{1},\left[\mathrm{Co}(\mathrm{bbp})(\mathrm{NCS})_{2}(\mathrm{DMF})\right]$ of $\mathbf{2}$, and $\left[\mathrm{Co}(\mathrm{bbp})(\mathrm{NCS})_{2}\right]$ of 3 . Plot of the d orbital splitting calculated by ab initio ligand field theory (AILFT) (left), low-lying ligand-field terms with various multiplicities (middle), and ligand-field multiplets showing the zero-field splitting (right).

the pentacoordinate $\left[\mathrm{Co}(\mathrm{bbp})(\mathrm{NCS})_{2}\right]$ complex of 3 to the hexacoordinate $\left[\mathrm{Co}(\mathrm{bbp})_{2}\right]^{2+}$ and $\left[\mathrm{Co}(\mathrm{bbp})(\mathrm{NCS})_{2}(\mathrm{DMF})\right]$ complexes of $\mathbf{1}$ and $\mathbf{2}$, respectively. In the case of ideal symmetry, we could expect two sets of e and $t_{2}$ orbitals for $T_{d}$ point group symmetry, four sets of e, $b_{2}, a_{1}$, and $b_{1}$ orbitals for $C_{4 v}$ point group symmetry, and finally two sets of $t_{2 g}$ and $e_{g}$ orbitals for $O_{h}$ point group symmetry. However, in all complexes the degeneracy of $\mathrm{d}$ orbitals is removed due to the nonhomogenous ligand field and lower symmetry of the coordination polyhedra (Figure 14, left). Calculated quartet and doublet ligand-field terms originating from the $3 \mathrm{~d}^{7}$ electron configuration are shown in Figure 14 (middle), where in all cases the quartet is the ground state, in agreement with the high-spin state of complexes under study. The subsequent spin-orbit interaction leads to the ligand-field multiplets, hence the zero-field splitting of $S=3 / 2$, which is clearly visible in Figure 14 (right). Large and positive $D$ parameters of $\sim 40-50 \mathrm{~cm}^{-1}$ were calculated for the [Co$\left.(\mathrm{bbp})_{2}\right]^{2+}$ complex of $\mathbf{1}$ and the $\left[\mathrm{Co}(\mathrm{bbp})(\mathrm{NCS})_{2}\right]$ complex of 3 , whereas a minute and negative $D$ parameter is found for the $\left[\mathrm{Co}(\mathrm{NCS})_{4}\right]^{2-}$ complex of 1 . The largest $D$ parameter was derived for the $\left[\mathrm{Co}(\mathrm{bbp})(\mathrm{NCS})_{2}(\mathrm{DMF})\right]$ complex of 2, reaching a value of $\sim 100 \mathrm{~cm}^{-1}$ (Table 2). However, the calculated $g$ tensor and $D$ tensor parameters for this complex may not be fully valid due to the existence of the low-lying excited states (Figure 14), which limit the applicability of the spin Hamiltonian approach. Therefore, we have analyzed the CASSCF/NEVPT2 zero-field multiplet energy levels arising from the splitting of the ${ }^{4} \mathrm{~T}_{1 \mathrm{~g}}$ ground term with the L-S Hamiltonian (eq 5). ${ }^{24}$ Fitting the energies of the six lowest Kramers doublets resulted in the following parameters: $\alpha \cdot \lambda=$ $-245 \mathrm{~cm}^{-1}, \Delta_{\mathrm{ax}}=-714 \mathrm{~cm}^{-1}$, and $\Delta_{\mathrm{rh}}=-151 \mathrm{~cm}^{-1}$ (Figure S35). To summarize, both methods dealing with the dynamic electron correlation provided similar ZFS parameters and, in general, there is good quantitative agreement with the parameters fitted from the experimental magnetic data of 1-3.

\section{DISCUSSION}

To discuss the relationship between the geometry of the coordination polyhedron and the magnetic anisotropy, we start with tetracoordinate $\mathrm{Co}^{\mathrm{II}}$ complexes. The structural parameter $\delta$ proposed by Boča et al. was based on two angles, $\angle(\mathrm{X}$-Co-X) $(\alpha)$ and $\angle(\mathrm{Y}-\mathrm{Co}-\mathrm{Y})(\beta)$ for $\left[\mathrm{CoX}_{2} \mathrm{Y}_{2}\right]$ complexes, as $\delta=$ $2 \alpha_{\mathrm{Td}}-(\alpha+\beta)$, where $\alpha_{\mathrm{Td}}=109.5^{\circ}$, and it was suggested that this should directly correlate with $D .^{77}$ A later study by Nemec et al. showed that such a relationship between $\delta$ and $D$ is not linear in general. ${ }^{78}$ In case of tetracoordinate $\left[\mathrm{Co}(\mathrm{NCS})_{4}\right]^{2-}$ of 1, the homoleptic nature of this complex made it difficult to calculate $\delta$; however, the symmetry is close to ideal $T_{d}$ symmetry for which $D=0$ and, indeed, the CASSCF/ NEVPT2 calculation resulted in a very small $D$ value of -1.23 $\mathrm{cm}^{-1}$ (Table 2). Also, other homoleptic tetrahedral complexes of $\mathrm{Co}^{\mathrm{II}}$ were studied, ${ }^{79}$ and an attempt to correlate $D$ with the continuous symmetry measure (CShM) of SHAPE was reported. $^{80}$

The pentacoordinate complexes usually varied between trigonal-bipyramidal and square-planar arrangements, where the latter can possess a large contribution of the angular orbital momentum to the ground state. Recently, the magnetostructural correlation of $D$ based on the Addison parameter $\tau$ was reported, showing that the square-pyramidal $\mathrm{Co}^{\mathrm{II}}$ complexes adopt large and negative $D$ values and, moreover, that the sign of $D$ is changed to positive on a transition to the chromophore geometries closer to the trigonal-bipyramidal arrangement, with the crossing point at $\tau \approx 0.3$. $^{76}$ Another correlation was later reported for complexes close to a trigonal- 
bipyramidal arrangement, for which small values of $|D|$ are expected. ${ }^{81}$ Thus, for a value of $\tau=0.28$ in 3 we could expect $|D|$ to be roughly around $40 \mathrm{~cm}^{-1}$, which was also found experimentally with $D=39.4 \mathrm{~cm}^{-1}$. Similar pentacoordinate complexes were also studied recently, and extensive modeling based on the CASSCF/DCD-CAS(2) method confirmed the huge potential of such molecular species for achieving systems with large axial magnetic anisotropy. ${ }^{82}$

The hexacoordinate $\mathrm{Co}^{\mathrm{II}}$ complexes are well-known to possess a ${ }^{4} \mathrm{~T}_{1 \mathrm{~g}}$ ground state in ideal $O_{h}$ symmetry, which, however, is prohibited by the Jahn-Teller theorem, leading to geometrical distortions. The foundations of the magnetism were originally laid down by Figgis ${ }^{83}$ and Griffith, ${ }^{68}$ as already mentioned during the analysis of compound 2. A lowering of the ligand field symmetry can lead to ${ }^{4} \mathrm{~A}$ or ${ }^{4} \mathrm{~B}$ well-isolated ground states, for which a spin Hamiltonian is an adequate model for the magnetism, and Boča et al. ${ }^{66}$ reported a nonlinear magneto-structural correlation for the axial and rhombic specifically defined structural parameters. Importantly, both positive and negative large $D$ values can be found in distorted-octahedral $\mathrm{Co}^{\mathrm{II}}$ complexes e.g. by synthetic modification of the tripodal ligands ${ }^{84}$ or by modification of the ligands in the axial positions, where in addition to CASSCF $a b$ initio methods also the AOM (angular overlap model) was successfully employed. ${ }^{85-87}$ Especially for these systems the theoretical methods are important to guide the interpretation of the magnetic data and the choice of the proper Hamiltonian model to use. This was exemplified in this work for $\left[\mathrm{Co}(\mathrm{bbp})_{2}\right]^{2+}$ of $\mathbf{1}$ and $\left[\mathrm{Co}(\mathrm{bbp})(\mathrm{NCS})_{2}(\mathrm{DMF})\right]$ of $\mathbf{2}$, in which a larger structural deviation from $O_{h}$ symmetry in the former made a spin Hamiltonian the right model to apply, whereas the latter compound was treated by a Figgis-Griffith Hamiltonian model.

\section{CONCLUSION}

Utilization of two different crystallization procedures for the products of the reaction between $\mathrm{Co}(\mathrm{NCS})_{2}$ and the bbp ligand resulted in the preparation of three distinct compounds: $\left[\mathrm{Co}(\mathrm{bbp})_{2}\right]\left[\mathrm{Co}(\mathrm{NCS})_{4}\right] \cdot 4 \mathrm{DMF}(\mathbf{1}),[\mathrm{Co}(\mathrm{bbp})-$ $\left.(\mathrm{NCS})_{2}(\mathrm{DMF})\right] \cdot 2 \mathrm{DMF}(2)$, and $\left[\mathrm{Co}(\mathrm{bbp})(\mathrm{NCS})_{2}\right]$ (3). Complex 1 shows a remarkably interesting structural transformation to form complex 2. Complex 1 contains two different $\mathrm{Co}(\mathrm{II})$ ions with different coordination geometries: octahedral $\left(\left[\mathrm{Co}(\mathrm{bbp})_{2}\right]^{2+}\right)$ and tetrahedral $\left(\left[\mathrm{Co}(\mathrm{NCS})_{4}\right]^{2-}\right)$, whereas the metal centers in $\mathbf{2}$ and $\mathbf{3}$ have distorted-octahedral $\left(\left[\mathrm{Co}(\mathrm{bbp})(\mathrm{NCS})_{2}(\mathrm{DMF})\right]\right)$ and distorted-square-pyramidal $\left(\left[\mathrm{Co}(\mathrm{bbp})(\mathrm{NCS})_{2}\right]\right)$ coordination geometries, respectively. These structural differences affect the magnetic anisotropy of these compounds significantly. In 1, the octahedral unit exhibits a large and positive parameter of axial magnetic anisotropy $\left(D=+39.0 \mathrm{~cm}^{-1}\right)$, whereas the tetracoordinate counteranion possesses only very small anisotropy, which was even neglected in a fitting of the magnetic data. Complex $\mathbf{2}$ has a ZFS parameter $D$ of $+69.5 \mathrm{~cm}^{-1}$ and exhibits a field-induced slow relaxation of magnetization under 1000 Oe dc field with a relaxation time of $1.9 \times 10^{-6} \mathrm{~s}$, whereas complex 3 has a ZFS parameter $D$ of $+38.1 \mathrm{~cm}^{-1}$ and also shows a field-induced magnetic relaxation under a 1500 Oe dc field with a relaxation time of $1.8 \times 10^{-5} \mathrm{~s}$. X-band EPR measurements and CASSCF/NEVPT2 calculations confirmed the stated results.

\section{AUTHOR INFORMATION}

\section{Corresponding Author}

Abhishake Mondal - Solid State and Structural Chemistry Unit, Indian Institute of Science, Bangalore 560012, India; ○ orcid.org/0000-0002-5061-2326; Email: mondal@ iisc.ac.in

\section{Authors}

Subrata Ghosh - Solid State and Structural Chemistry Unit, Indian Institute of Science, Bangalore 560012, India; (1) orcid.org/0000-0003-4539-4413

Sujit Kamilya - Solid State and Structural Chemistry Unit, Indian Institute of Science, Bangalore 560012, India; (i) orcid.org/0000-0003-4881-0638

Mayurika Das - Solid State and Structural Chemistry Unit, Indian Institute of Science, Bangalore 560012, India; (1) orcid.org/0000-0002-2907-9854

Sakshi Mehta - Solid State and Structural Chemistry Unit, Indian Institute of Science, Bangalore 560012, India; (1) orcid.org/0000-0002-1232-4489

Marie-Emmanuelle Boulon - Photon Science Institute, Alan Turing Building, office 3.315, The University of Manchester, Manchester M13 9PL, United Kingdom; O orcid.org/00000003-1837-0803

Ivan Nemec - Department of Inorganic Chemistry, Faculty of Science, Palacký University, CZ-771 46 Olomouc, Czech Republic; Central European Institute of Technology, CEITEC BUT, 61600 Brno, Czech Republic; (1) orcid.org/0000-00033231-7849

Mathieu Rouzières - Univ. Bordeaux, CNRS, Centre de Recherche Paul Pascal, CRPP, UMR 5031, 33600 Pessac, France; orcid.org/0000-0003-3457-3133

Radovan Herchel - Department of Inorganic Chemistry, Faculty of Science, Palacky University, CZ-771 46 Olomouc, Czech Republic; $\bigcirc$ orcid.org/0000-0001-8262-4666

\section{ACKNOWLEDGMENTS}

This research work was supported by the Indian Institute of Science (IISc), Bangalore, India, and the Science \& Engineering Research Board (SERB) (Project No. SRG/2019/000317). 
We are thankful to the IISc and Ministry of Human Resource Development (MHRD), Government of India, for funding the Start-up Research Grant (SG/MHRD-17-0014 and SR/ MHRD-17-0011). S.G., M.D., and S.M. thank the IISc and S.K. thanks the Council of Scientific \& Industrial Research (CSIR), Government of India, for their fellowships. R.H. and I.N. acknowledge financial support from institutional sources of the Department of Inorganic Chemistry, Palacký University Olomouc, Czech Republic. I.N. acknowledges the project CEITEC 2020 (LQ1601) with financial support from the Ministry of Education, Youth and Sports of the Czech Republic under the National Sustainability Programme II. Dilip Kumar Maity is thanked for useful discussion. M.-E.B. thanks the Engineering and Physical Sciences Research Council (EPSRC) for funding her postdoctoral position through grant EP/L018470/1 and the EPSRC National Electron Paramagnetic Resonance Facility and Service at the University of Manchester, where the experiments were held.

\section{REFERENCES}

(1) Feng, M.; Tong, M.-L. Single Ion Magnets from 3d to 5f: Developments and Strategies. Chem. - Eur. J. 2018, 24 (30), 75747594.

(2) Chakraborty, A.; Goura, J.; Kalita, P.; Swain, A.; Rajaraman, G.; Chandrasekhar, V. Heterometallic $3 \mathrm{~d}-4 \mathrm{f}$ single molecule magnets containing diamagnetic metal ions. Dalton Trans. 2018, 47 (27), $8841-8864$.

(3) Ferrando-Soria, J.; Vallejo, J.; Castellano, M.; Martínez-Lillo, J.; Pardo, E.; Cano, J.; Castro, I.; Lloret, F.; Ruiz-García, R.; Julve, M. Molecular magnetism, quo vadis? A historical perspective from a coordination chemist viewpoint is. Coord. Chem. Rev. 2017, 339, 17103.

(4) Sessoli, R. Nanoscience: Single-atom data storage. Nature 2017, 543 (7644), 189-190.

(5) Natterer, F. D.; Yang, K.; Paul, W.; Willke, P.; Choi, T.; Greber, T.; Heinrich, A. J.; Lutz, C. P. Reading and writing single-atom magnets. Nature 2017, 543 (7644), 226-228.

(6) Baumann, S.; Paul, W.; Choi, T.; Lutz, C. P.; Ardavan, A.; Heinrich, A. J. Electron paramagnetic resonance of individual atoms on a surface. Science 2015, 350 (6259), 417-420.

(7) Ako, A. M.; Hewitt, I. J.; Mereacre, V.; Clérac, R.; Wernsdorfer, W.; Anson, C. E.; Powell, A. K. A Ferromagnetically Coupled Mn19 Aggregate with a Record S $=83 / 2$ Ground Spin State. Angew. Chem., Int. Ed. 2006, 45 (30), 4926-4929.

(8) Sessoli, R.; Tsai, H. L.; Schake, A. R.; Wang, S.; Vincent, J. B.; Folting, K.; Gatteschi, D.; Christou, G.; Hendrickson, D. N. High-spin molecules: [Mn12O12(O2CR)16(H2O)4]. J. Am. Chem. Soc. 1993, 115 (5), 1804-1816.

(9) Sessoli, R.; Gatteschi, D.; Caneschi, A.; Novak, M. A. Magnetic bistability in a metal-ion cluster. Nature 1993, 365 (6442), 141.

(10) Frost, J. M.; Harriman, K. L. M.; Murugesu, M. The rise of 3-d single-ion magnets in molecular magnetism: towards materials from molecules? Chem. Sci. 2016, 7 (4), 2470-2491.

(11) Craig, G. A.; Murrie, M. 3d single-ion magnets. Chem. Soc. Rev. 2015, 44 (8), 2135-2147.

(12) Guo, F.-S.; Day, B. M.; Chen, Y.-C.; Tong, M.-L.; Mansikkamäki, A.; Layfield, R. A. Magnetic hysteresis up to $80 \mathrm{~K}$ in a dysprosium metallocene single-molecule magnet. Science 2018, 362 (6421), 1400-1403.

(13) Guo, F.-S.; Day, B. M.; Chen, Y.-C.; Tong, M.-L.; Mansikkamäki, A.; Layfield, R. A. A Dysprosium Metallocene Single-Molecule Magnet Functioning at the Axial Limit. Angew. Chem., Int. Ed. 2017, 56 (38), 11445-11449.

(14) Goodwin, C. A. P.; Ortu, F.; Reta, D.; Chilton, N. F.; Mills, D. $\mathrm{P}$. Molecular magnetic hysteresis at $60 \mathrm{~K}$ in dysprosocenium. Nature 2017, 548 (7668), 439-442.
(15) Ishikawa, N.; Sugita, M.; Ishikawa, T.; Koshihara, S.-y.; Kaizu, Y. Lanthanide Double-Decker Complexes Functioning as Magnets at the Single-Molecular Level. J. Am. Chem. Soc. 2003, 125 (29), 86948695.

(16) Craig, G. A.; Sarkar, A.; Woodall, C. H.; Hay, M. A.; Marriott, K. E. R.; Kamenev, K. V.; Moggach, S. A.; Brechin, E. K.; Parsons, S.; Rajaraman, G.; Murrie, M. Probing the origin of the giant magnetic anisotropy in trigonal bipyramidal $\mathrm{Ni}(\mathrm{II})$ under high pressure. Chem. Sci. 2018, 9 (6), 1551-1559.

(17) Bhowmick, I.; Roehl, A. J.; Neilson, J. R.; Rappé, A. K.; Shores, M. P. Slow magnetic relaxation in octahedral low-spin $\mathrm{Ni}(\mathrm{III})$ complexes. Chem. Sci. 2018, 9 (31), 6564-6571.

(18) Lin, C.-Y.; Ngendahimana, T.; Eaton, G. R.; Eaton, S. S.; Zadrozny, J. M. Counterion influence on dynamic spin properties in a V(IV) complex. Chem. Sci. 2019, 10 (2), 548-555.

(19) Rajnák, C.; Titiš, J.; Moncol, J.; Mičová, R.; Boča, R. FieldInduced Slow Magnetic Relaxation in a Mononuclear Manganese(II) Complex. Inorg. Chem. 2019, 58 (2), 991-994.

(20) Bar, A. K.; Pichon, C.; Sutter, J.-P. Magnetic anisotropy in twoto eight-coordinated transition-metal complexes: Recent developments in molecular magnetism. Coord. Chem. Rev. 2016, 308, 346380.

(21) Drahoš, B.; Herchel, R.; Trávníček, Z. Impact of Halogenido Coligands on Magnetic Anisotropy in Seven-Coordinate Co(II) Complexes. Inorg. Chem. 2017, 56 (9), 5076-5088.

(22) Váhovská, L.; Bukrynov, O.; Potočňák, I.; Čižmár, E.; Kliuikov, A.; Vitushkina, S.; Dušek, M.; Herchel, R. New Cobalt(II) FieldInduced Single-Molecule Magnet and the First Example of a Cobalt(III) Complex with Tridentate Binding of a Deprotonated 4Amino-3,5-bis(pyridin-2-yl)-1,2,4-Triazole Ligand: New Cobalt(II) Field-Induced Single-Molecule Magnet and the First Example of a Cobalt(III) Complex with Tridentate Binding of a Deprotonated 4Amino-3. Eur. J. Inorg. Chem. 2019, 2019 (2), 250-261.

(23) Świtlicka, A.; Palion-Gazda, J.; Machura, B.; Cano, J.; Lloret, F.; Julve, M. Field-induced slow magnetic relaxation in pseudooctahedral cobalt(II) complexes with positive axial and large rhombic anisotropy. Dalton Trans. 2019, 48 (4), 1404-1417.

(24) Nemec, I.; Herchel, R.; Trávníček, Z. Two polymorphic Co(II) field-induced single-ion magnets with enormous angular distortion from the ideal octahedron. Dalton Trans. 2018, 47 (5), 1614-1623.

(25) Shao, F.; Cahier, B.; Guihéry, N.; Rivière, E.; Guillot, R.; Barra, A.-L.; Lan, Y.; Wernsdorfer, W.; Campbell, V. E.; Mallah, T. Tuning the Ising-type anisotropy in trigonal bipyramidal $\mathrm{Co}(\mathrm{II})$ complexes. Chem. Commun. 2015, 51 (92), 16475-16478.

(26) Bunting, P. C.; Atanasov, M.; Damgaard-Møller, E.; Perfetti, M.; Crassee, I.; Orlita, M.; Overgaard, J.; Slageren, J. v.; Neese, F.; Long, J. R. A linear cobalt(II) complex with maximal orbital angular momentum from a non-Aufbau ground state. Science 2018, 362 (6421), No. eaat7319.

(27) Jin, X.-X.; Chen, X.-X.; Xiang, J.; Chen, Y.-Z.; Jia, L.-H.; Wang, B.-W.; Cheng, S.-C.; Zhou, X.; Leung, C.-F.; Gao, S. Slow Magnetic Relaxation in a Series of Mononuclear 8-Coordinate $\mathrm{Fe}(\mathrm{II})$ and Co(II) Complexes. Inorg. Chem. 2018, 57 (7), 3761-3774.

(28) Mitsuhashi, R.; Hosoya, S.; Suzuki, T.; Sunatsuki, Y.; Sakiyama, H.; Mikuriya, M. Hydrogen-bonding interactions and magnetic relaxation dynamics in tetracoordinated cobalt(II) single-ion magnets. Dalton Trans. 2019, 48 (2), 395-399.

(29) Vallejo, J.; Pardo, E.; Viciano-Chumillas, M.; Castro, I.; Amorós, P.; Déniz, M.; Ruiz-Pérez, C.; Yuste-Vivas, C.; Krzystek, J.; Julve, M.; Lloret, F.; Cano, J. Reversible solvatomagnetic switching in a single-ion magnet from an entatic state. Chem. Sci. 2017, 8 (5), 3694-3702.

(30) Rechkemmer, Y.; Breitgoff, F. D.; van der Meer, M.; Atanasov, M.; Hakl, M.; Orlita, M.; Neugebauer, P.; Neese, F.; Sarkar, B.; van Slageren, J. A four-coordinate cobalt(II) single-ion magnet with coercivity and a very high energy barrier. Nat. Commun. 2016, 7, 10467.

(31) Sertphon, D.; Murray, K. S.; Phonsri, W.; Jover, J.; Ruiz, E.; Telfer, S. G.; Alkaş, A.; Harding, P.; Harding, D. J. Slow relaxation of 
magnetization in a bis-mer-tridentate octahedral $\mathrm{Co}$ (ii) complex. Dalton Trans. 2018, 47 (3), 859-867.

(32) Hong, S. Y.; Kwak, J.; Chang, S. Rhodium-catalyzed selective $\mathrm{C}-\mathrm{H}$ functionalization of NNN tridentate chelating compounds via a rollover pathway. Chem. Commun. 2016, 52 (15), 3159-3162.

(33) Degen, T.; Sadki, M.; Bron, E.; König, U.; Nénert, G. The HighScore suite. Powder Diffr. 2014, 29 (S2), S13-S18.

(34) Stoll, S.; Schweiger, A. EasySpin, a comprehensive software package for spectral simulation and analysis in EPR. J. Magn. Reson. 2006, 178 (1), 42-55.

(35) Sheldrick, G. M. SADABS, Ver. 2.03; Bruker Analytical X-Ray Systems: Madison, WI, USA, 2000.

(36) Sheldrick, G. Crystal structure refinement with SHELXL. Acta Crystallogr., Sect. C: Struct. Chem. 2015, 71 (1), 3-8.

(37) Neese, F. Software update: the ORCA program system, version 4.0. Wiley Interdiscip. Rev.: Comput. Mol. Sci. 2018, 8 (1), No. e1327.

(38) Neese, F. The ORCA program system. Wiley Interdiscip. Rev.: Comput. Mol. Sci. 2012, 2 (1), 73-78.

(39) Malmqvist, P.-Å.; Roos, B. O. The CASSCF state interaction method. Chem. Phys. Lett. 1989, 155 (2), 189-194.

(40) Angeli, C.; Cimiraglia, R.; Malrieu, J.-P. n-electron valence state perturbation theory: A spinless formulation and an efficient implementation of the strongly contracted and of the partially contracted variants. J. Chem. Phys. 2002, 117 (20), 9138-9153.

(41) Angeli, C.; Cimiraglia, R.; Evangelisti, S.; Leininger, T.; Malrieu, J.-P. Introduction of n-electron valence states for multireference perturbation theory. J. Chem. Phys. 2001, 114 (23), 1025210264.

(42) Weigend, F.; Ahlrichs, R. Balanced basis sets of split valence, triple zeta valence and quadruple zeta valence quality for $\mathrm{H}$ to $\mathrm{Rn}$ : Design and assessment of accuracy. Phys. Chem. Chem. Phys. 2005, 7 (18), 3297-3305.

(43) Ganyushin, D.; Neese, F. First-principles calculations of zerofield splitting parameters. J. Chem. Phys. 2006, 125 (2), 024103.

(44) Neese, F. Efficient and accurate approximations to the molecular spin-orbit coupling operator and their use in molecular gtensor calculations. J. Chem. Phys. 2005, 122 (3), 034107.

(45) Maurice, R.; Bastardis, R.; Graaf, C. d.; Suaud, N.; Mallah, T.; Guihéry, N. Universal Theoretical Approach to Extract Anisotropic Spin Hamiltonians. J. Chem. Theory Comput. 2009, 5 (11), 29772984.

(46) Weigend, F. Accurate Coulomb-fitting basis sets for $\mathrm{H}$ to $\mathrm{Rn}$. Phys. Chem. Chem. Phys. 2006, 8 (9), 1057-1065.

(47) Hellweg, A.; Hättig, C.; Höfener, S.; Klopper, W. Optimized accurate auxiliary basis sets for RI-MP2 and RI-CC2 calculations for the atoms $\mathrm{Rb}$ to $\mathrm{Rn}$. Theor. Chem. Acc. 2007, 117 (4), 587-597.

(48) Singh, S. K.; Eng, J.; Atanasov, M.; Neese, F. Covalency and chemical bonding in transition metal complexes: An ab initio based ligand field perspective. Coord. Chem. Rev. 2017, 344, 2-25.

(49) Mingos, D. M. P.; Day, P.; Dahl, J. P. Molecular Electronic Structures of Transition Metal Complexes II; Springer Berlin: Berlin, 2014.

(50) Pathak, S.; Lang, L.; Neese, F. A dynamic correlation dressed complete active space method: Theory, implementation, and preliminary applications. J. Chem. Phys. 2017, 147 (23), 234109.

(51) Alemany, S. A.; Pinsky, M.; Avnir, D. SHAPE, ver. 2; Barcelona, 2005

(52) Addison, A. W.; Rao, T. N.; Reedijk, J.; van Rijn, J.; Verschoor, G. C. Synthesis, structure, and spectroscopic properties of copper(II) compounds containing nitrogen-sulphur donor ligands; the crystal and molecular structure of aqua[1,7-bis( $\mathrm{N}$-methylbenzimidazol-2'yl)-2,6-dithiaheptane]copper(II) perchlorate. J. Chem. Soc., Dalton Trans. 1984, No. 7, 1349-1356.

(53) Shankar, K.; Mondal, A.; Li, Y.; Journaux, Y.; Baruah, J. B. Hydroxide-Bridged Mixed-Valence Tetranuclear Cobalt 4-Nitrophenol Inclusion Complex Showing Single Molecule Magnet Property. Chemistry Select 2017, 2 (26), 7792-7798.

(54) Khakhlary, P.; Anson, C. E.; Mondal, A.; Powell, A. K.; Baruah, J. B. Structural and magnetic properties of oxyquinolinate clusters of cobalt(ii) and manganese(ii) and serendipitous intake of carbonate during synthesis. Dalton Trans. 2015, 44 (7), 2964-2969.

(55) Mondal, A.; Li, Y.; Seuleiman, M.; Julve, M.; Toupet, L.; BuronLe Cointe, M.; Lescouëzec, R. On/Off Photoswitching in a CyanideBridged \{Fe2Co2\} Magnetic Molecular Square. J. Am. Chem. Soc. 2013, 135 (5), 1653-1656.

(56) Mondal, A.; Durdevic, S.; Chamoreau, L.-M.; Journaux, Y.; Julve, M.; Lisnard, L.; Lescouëzec, R. A cyanide and hydroxo-bridged nanocage: a new generation of coordination clusters. Chem. Commun. 2013, 49 (12), 1181-1183.

(57) Mondal, A.; Chamoreau, L.-M.; Li, Y.; Journaux, Y.; Seuleiman, M.; Lescouëzec, R. W-Co Discrete Complex Exhibiting Photo- and Thermo-Induced Magnetisation. Chem. - Eur. J. 2013, 19 (24), 76827685.

(58) Lloret, F.; Julve, M.; Cano, J.; Ruiz-García, R.; Pardo, E. Magnetic properties of six-coordinated high-spin cobalt(II) complexes: Theoretical background and its application. Inorg. Chim. Acta 2008, 361 (12), 3432-3445.

(59) Drath, O.; Boskovic, C. Switchable cobalt coordination polymers: Spin crossover and valence tautomerism. Coord. Chem. Rev. 2018, 375, 256-266.

(60) McPherson, J. N.; Hogue, R. W.; Akogun, F. S.; Bondì, L.; Luis, E. T.; Price, J. R.; Garden, A. L.; Brooker, S.; Colbran, S. B. Predictable Substituent Control of CoIII/II Redox Potential and Spin Crossover in Bis(dipyridylpyrrolide)cobalt Complexes. Inorg. Chem. 2019, 58 (3), 2218-2228.

(61) Miller, R. G.; Narayanaswamy, S.; Tallon, J. L.; Brooker, S. Spin crossover with thermal hysteresis in cobalt(ii) complexes and the importance of scan rate. New J. Chem. 2014, 38 (5), 1932-1941.

(62) Habib, F.; Luca, O. R.; Vieru, V.; Shiddiq, M.; Korobkov, I.; Gorelsky, S. I.; Takase, M. K.; Chibotaru, L. F.; Hill, S.; Crabtree, R. H.; Murugesu, M. Influence of the Ligand Field on Slow Magnetization Relaxation versus Spin Crossover in Mononuclear Cobalt Complexes. Angew. Chem., Int. Ed. 2013, 52 (43), 1129011293.

(63) Krivokapic, I.; Zerara, M.; Daku, M. L.; Vargas, A.; Enachescu, C.; Ambrus, C.; Tregenna-Piggott, P.; Amstutz, N.; Krausz, E.; Hauser, A. Spin-crossover in cobalt(II) imine complexes. Coord. Chem. Rev. 2007, 251 (3), 364-378.

(64) Boča, R. A Handbook of Magnetochemical Formulae; Elsevier: 2012.

(65) Boca, R.; Mingos, D. M. P. Magnetic functions beyond the spinHamiltonian; Springer: Berlin, 2006.

(66) Titiš, J.; Boča, R. Magnetostructural D Correlations in Hexacoordinated Cobalt(II) Complexes. Inorg. Chem. 2011, 50 (22), 11838-11845

(67) Figgis, B. N.; Gerloch, M.; Lewis, J.; Mabbs, F. E.; Webb, G. A. The magnetic behaviour of cubic-field $4 \mathrm{~T} 1 \mathrm{~g}$ terms in lower symmetry. J. Chem. Soc. A 1968, No. 0, 2086-2093.

(68) Griffith, J. S. The theory of transition-metal ions; Cambridge University Press: Cambridge, 1961.

(69) Boca, R. A handbook of magnetochemical formulae; Elsevier: 2012.

(70) Rajnák, C.; Varga, F.; Titiš, J.; Moncol, J.; Boča, R. Octahedral-Tetrahedral Systems $[\mathrm{Co}(\mathrm{dppmO}, \mathrm{O}) 3] 2+[\mathrm{CoX} 4] 2-$ Showing Slow Magnetic Relaxation with Two Relaxation Modes. Inorg. Chem. 2018, 57 (8), 4352-4358.

(71) Kalinke, L. H. G.; Cardoso, J. C. O.; Rabelo, R.; Valdo, A. K.; Martins, F. T.; Cano, J.; Julve, M.; Lloret, F.; Cangussu, D. From Paramagnetic to Single-Molecule Magnet Behaviour in Heterobimetallic Compounds Containing the Tetrakis(thiocyanato- $\kappa \mathrm{N}$ ) cobaltate(II) Anion. Eur. J. Inorg. Chem. 2018, 2018 (6), 816-825.

(72) Zhu, Y.-Y.; Liu, F.; Liu, J.-J.; Meng, Y.-S.; Jiang, S.-D.; Barra, A.L.; Wernsdorfer, W.; Gao, S. Slow Magnetic Relaxation in Weak EasyPlane Anisotropy: the Case of a Combined Magnetic and HFEPR Study. Inorg. Chem. 2017, 56 (2), 697-700.

(73) Shao, D.; Deng, L.-D.; Shi, L.; Wu, D.-Q.; Wei, X.-Q.; Yang, S.R.; Wang, X.-Y. Slow Magnetic Relaxation and Spin-Crossover 
Behavior in a Bicomponent Ion-Pair Cobalt(II) Complex. Eur. J. Inorg. Chem. 2017, 2017 (33), 3862-3867.

(74) Cole, K. S.; Cole, R. H. Dispersion and Absorption in Dielectrics I. Alternating Current Characteristics. J. Chem. Phys. 1941, 9 (4), 341-351.

(75) Mondal, A. K.; Goswami, T.; Misra, A.; Konar, S. Probing the Effects of Ligand Field and Coordination Geometry on Magnetic Anisotropy of Pentacoordinate Cobalt(II) Single-Ion Magnets. Inorg. Chem. 2017, 56 (12), 6870-6878.

(76) Nemec, I.; Liu, H.; Herchel, R.; Zhang, X.; Trávníček, Z. Magnetic anisotropy in pentacoordinate 2,6-bis(arylazanylidene-1chloromethyl)pyridine cobalt(II) complexes with chlorido co-ligands. Synth. Met. 2016, 215, 158-163.

(77) Titiš, J.; Miklovič, J.; Boča, R. Magnetostructural study of tetracoordinate cobalt(II) complexes. Inorg. Chem. Commun. 2013, $35,72-75$.

(78) Nemec, I.; Herchel, R.; Kern, M.; Neugebauer, P.; Van Slageren, J.; Trávnícek, Z. Magnetic Anisotropy and Field-induced Slow Relaxation of Magnetization in Tetracoordinate CoII Compound [Co(CH3-im)2Cl2]. Materials 2017, 10 (3), 249.

(79) Sottini, S.; Poneti, G.; Ciattini, S.; Levesanos, N.; Ferentinos,

E.; Krzystek, J.; Sorace, L.; Kyritsis, P. Magnetic Anisotropy of Tetrahedral CoII Single-Ion Magnets: Solid-State Effects. Inorg. Chem. 2016, 55 (19), 9537-9548.

(80) Wu, T.; Zhai, Y.-Q.; Deng, Y.-F.; Chen, W.-P.; Zhang, T.; Zheng, Y.-Z. Correlating magnetic anisotropy with the subtle coordination geometry variation of a series of cobalt(ii)-sulfonamide complexes. Dalton Trans. 2019, 48 (41), 15419-15426.

(81) Massoud, S. S.; Fischer, R. C.; Mautner, F. A.; Parfait, M. M.; Herchel, R.; Trávníček, Z. Pentacoordinate cobalt(II) complexes with neutral tripodal $\mathrm{N}$-donor ligands: Zero-field splitting for a distorted trigonal bipyramidal geometry. Inorg. Chim. Acta 2018, 471, 630-639. (82) Brachňaková, B.; Matejová, S.; Moncol, J.; Herchel, R.; Pavlik, J.; Moreno-Pineda, E.; Ruben, M.; Salitroš, I. Stereochemistry of coordination polyhedra vs. single ion magnetism in penta- and hexacoordinated $\mathrm{Co}(\mathrm{ii})$ complexes with tridentate rigid ligands. Dalton Trans. 2020, 49 (4), 1249-1264.

(83) Figgis, B. N. Ligand field theory and its applications; Wiley-VCH: New York, 2000.

(84) Ding, Z.-Y.; Meng, Y.-S.; Xiao, Y.; Zhang, Y.-Q.; Zhu, Y.-Y.; Gao, S. Probing the influence of molecular symmetry on the magnetic anisotropy of octahedral cobalt(ii) complexes. Inorg. Chem. Front. 2017, 4 (11), 1909-1916.

(85) Herchel, R.; Váhovská, L.; Potočňák, I.; Trávníček, Z. Slow Magnetic Relaxation in Octahedral Cobalt(II) Field-Induced SingleIon Magnet with Positive Axial and Large Rhombic Anisotropy. Inorg. Chem. 2014, 53 (12), 5896-5898.

(86) Váhovská, L.; Vitushkina, S.; Potočnák, I.; Trávníček, Z.; Herchel, R. Effect of linear and non-linear pseudohalides on the structural and magnetic properties of $\mathrm{Co}(\mathrm{ii})$ hexacoordinate singlemolecule magnets. Dalton Trans. 2018, 47 (5), 1498-1512.

(87) Váhovská, L.; Bukrynov, O.; Potočňák, I.; Čižmár, E.; Kliuikov, A.; Vitushkina, S.; Dušek, M.; Herchel, R. New Cobalt(II) FieldInduced Single-Molecule Magnet and the First Example of a Cobalt(III) Complex with Tridentate Binding of a Deprotonated 4Amino-3,5-bis(pyridin-2-yl)-1,2,4-Triazole Ligand. Eur. J. Inorg. Chem. 2019, 2019 (2), 250-261. 